PCMDI Report No. 32

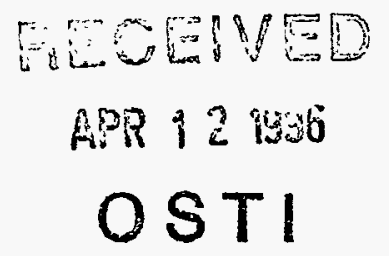

\title{
INTERCOMPARISON OF LOW-FREQUENCY VARIABILITY OF THE GLOBAL 200 hPa CIRCULATION FOR AMIP SIMULATIONS
}

by

James S. Boyle

Program for Climate Model Diagnosis and Intercomparison Lawrence Livermore National Laboratory, Livermore, CA, USA

March 1996

PROGRAM FOR CLIMATE MODEL DIAGNOSIS AND INTERCOMPARISON UNIVERSITY OF CALIFORNIA, LAWRENCE LIVERMORE NATIONAL LABORATORY LIVERMORE, CA 94550 


\title{
Intercomparison of Low-Frequency Variability of the global $200 \mathrm{hPa}$ Circulation for AMIP Simulations
}

\author{
by \\ James S. Boyle \\ Program for Climate Model Diagnosis and Intercomparison \\ Lawrence Livermore National Laboratory \\ Livermore, CA USA
}

March 1996 


\begin{abstract}
In the Atmospheric Model Intercomparison Project (AMIP) a number of GCMs are integrated for a 10 year period, 1979-1988, all using the same monthly mean sea surface temperature (SST). This permits a useful intercomparison of the response of the models to the imposed SST. The variables used here for the intercomparison are the $200 \mathrm{hPa}$ divergence and streamfunction. The data used are in the form of monthly averages and are filtered to a spatial resolution of $\mathrm{T} 10$, although the actual spatial resolution of the models varies from R15 to T42. The data are manipulated in this manner to concentrate on the low frequency, large scale response. The tools of the analysis are principal components analysis (PCA) and common principal components (CPC). These analyses are carried out on the 120 months of data with the seasonal cycle removed and in the case of the streamfunction with the zonal average also removed. The 1979-1988 period encompasses two El Niño / Southern Oscillation (ENSO) events (1982/83 and 1986/87), and as could be expected the ENSO characteristic response has a prominent impact in the model simulations.

The results indicate that:

(1) The PCA of the divergence has a dominant mode which is similar for all the models and has the signature of an (ENSO) response. It has an east-west dipole of divergence anomaly centered on the equator in the western Pacific. This mode accounts for $29 \%$ to $53 \%$ of the explained variance for the models considered.

(2) The streamfunction PC analysis also exhibits an ENSO type response as the dominant mode, but this accounts for only $8 \%$ to $21 \%$ of the variance.

(3) The CPC analysis allows a direct comparison of the data from all the models on a common set of vectors. The component identified with the ENSO mode represents $27 \%$ to $52 \%$ of the variance explained for the divergence in this formulation. These results indicate that the models share a basic common pattern but there is a strong variation in the amplitude of the corresponding modes.

(4) The variance explained by the leading mode for the CPC streamfunction between $5 \%$ and $19 \%$, and there is less commonality in the higher components than seen in the divergence. This appears to be related to the stronger streamfunction response in the mid-latitudes, which is presumably more affected by non-linearity and intrinsic variability of the model integrations.
\end{abstract}


(5) Based on results using an ensemble of five decadal runs using the ECMWF GCM an estimate is made of the variation of explained variance due to intrinsic variability for a single model. It is found that in general the inter-model variation is somewhat greater than the intra-model ensemble variation using the ECMWF model.

(6) A probability density function (PDF) analysis in the space spanned by the first two CPCs for the velocity potential (which explain over $70 \%$ of the variance for all but one model) yields distinctive dynamical signatures. Some models populate a somewhat larger PDF space than others.

There is a strong implication that the models differ beyond the variation due to intrinsic variability in the dynamical system. Some of the models have distinctly different responses to a common SST forcing. The disparate results indicate that consensus on the representation of the physics of the atmosphere has not been reached, and the present uncertainty in the parameterizations is greater than the intrinsic uncertainty of the model system as shown by ensemble simulations. 


\section{Introduction}

This paper presents a comparison of the global, monthly mean anomalies of the $200 \mathrm{hPa}$ flow fields from a number of atmospheric general circulation models (GCMs) for a ten year integration using common, prescribed sea surface temperatures ( SST). The intent is to determine the nature of the agreement between the models and their relation to the observational data that are available.

The Atmospheric Model Intercomparison Project (AMIP) of the World Climate Research Programme's Working Group on Numerical Experimentation (WGNE) permits some insight as to the general nature of the model GCM response to SST variations. The participants in AMIP simulated the global atmosphere for the decade 1979 to 1988 using a common solar constant, $\mathrm{CO} 2$ concentration, and a common monthly averaged SST and sea ice data set. An overview of AMIP is provided by Gates (1992). The AMIP experimental protocol provides for a common external forcing in the form of specified SST, which allows for some assessment of the extent to which the models have a common low frequency response to identical external forcing. The individual models' land surface characteristics are not specified.

The AMIP models used in this study are identified in Table 1 where their horizontal and vertical resolutions are shown. As important as the spatial configuration of the model are the parameterizations used to simulate convective heating, heat flux, moisture flux, precipitation, clouds, and so forth. The complete specification of the parameterizations used in the models are described in Phillips (1994). The various penetrative convective parameterizations are probably crucial in the tropical SST response, but it is difficult to succinctly characterize them. For a specific scheme, say the Kuo scheme, there are so many variations and critical differences in implementation that simply identifying a parameterization by a single nomenclature can be misleading.

The low frequency response of the atmosphere to anomalies of sea surface temperature (SST) has been the subject of intensive investigation since the realization of the global implications that such fluctuations have on the climate. Bjerknes (1969) reviews previous observational studies and outlines a dynamical framework in which the tropical SST fluctuations have an impact on the global climate. In a number of studies, general circulation models have been used to investigate the relationship between sea surface temperature anomalies and the atmospheric response, Blackmon 
et al. (1983), Boer (1985, 1989), Lau, (1985), Palmer and Mansfield (1986), and Shukla and Fennessy (1988). Most of these studies have focused on the El Niño/Southern Oscillation (ENSO) response and have demonstrated that the GCMs produce a reasonable simulation in the tropics if the appropriate SSTs are specified. This work has indicated that a substantial part of the interannual variability of the models in the tropics is attributable to the effects of the SST variations.

Boer (1989) showed that a linearization about a zonal mean basic state is insufficient to describe the global response to the SST. He also demonstrated that while a linearization about a three dimensional basic state was adequate for the Tropics, the mid-latitude response was so strongly non-linear that this linearization was useless. Hoerling et al. (1992) also note that while the Gill (1980) linear model can account for most of the tropical SST response, the extratropics are considerably more complicated. As described by Tribbia (1991) the response in the extratropics depends in a nonlinear fashion on the strength and position of the subtropical jets. Thus even in the conceptual case of identical local responses to tropical SST variations, two models might still exhibit differences due to variations in the basic state extratropical wind fields. Since the current generation of GCMs do produce climatologies that have discernible biases with respect to each other and the observations, Boer's work would indicate that the models might strongly diverge in their response in midlatitudes to SST forcing. Indeed, given this sensitivity it is not clear that even multiple realizations of a given GCM will agree as to the response. Hoerling et al. (1992) indicate that the extratropical response is sensitive to the GCM employed. It is not entirely clear at present how the SST variations are translated into the low frequency oscillations in the upper level tropical flow, and even less certain how the effects are propagated into the extratropics. In addition, it has been found in GCM experiments that extratropical low frequency oscillations can take place in the absence of oscillating external boundary conditions, ( Lau, 1981, and MacVean, 1985). There are a number of proposed mechanisms for this internal source of atmospheric low frequency variability, among which are forcing by extratropical high-frequency transients, energy conversion from the standing waves to low frequency modes, and variations in the zonal mean flow altering the propagation characteristics of the atmosphere, (Branstator 1992, Metz 1994).

It should be emphasized that the analysis presented here cannot establish the ultimate superiority of one model over another. Experience with the AMIP data indi- 
cates that the models are not uniform in their regional or temporal performance. A model which performs well in one region or at a given time may perform poorly in other regions or at other times, and vice versa. In addition, the verification data are questionable enough to make the unambiguous decision of model correctness difficult. There is also a serious sampling problem in using only a single run of each GCM. Intrinsic variability may by chance bring a specific run of one model more in accord with observations compared with a single run of another model, but the situation may be reversed in different realizations of the two models. Thus, the results presented here should be viewed as an indication of the present consensus among the models, and the spectrum of model response to the imposed SST for the variables considered. It has been well established that the present generation of GCMs can mimic a reasonable tropical response. The question of how this tropical response is connected to the low frequency patterns over the globe is not yet a settled question, and perhaps the perspective of the AMIP models can shed some light on the nature of the response and the state of atmospheric modeling.

This work is not intended to be a catalog of the various recurrent patterns documented in the literature, (Wallace and Gutzler1981, Barnston and Livezey 1987), but it is an attempt to compare the modes that are dominant in the models, whatever they may be.

\section{Data and data procedures}

The data are 120 monthly means for the period January 1979 to December 1988. The variables used are the streamfunction and velocity potential at $200 \mathrm{hPa}$. The data are provided on the native grid of the specific model. For spectral models this is a Gaussian grid, while for the gridpoint models it is usually a regular latitude, longitude grid. The computation of the streamfunction and velocity potential and the interpolation from the model vertical coordinates to $200 \mathrm{hPa}$ was performed by the modeling group performing the integrations. Table 1 provides a list of the models that are used in this work. The data are transformed from the original grid to spherical harmonics using the NCAR SPHEREPACK code. The spherical harmonic coefficients are manipulated to eliminate the zonal mean and to establish a common triangular truncation at $\mathrm{T} 10$ for all models. These procedures restrict the analysis to the large

scale, stationary waves. In the time domain the ten year average for each month is 
removed from the data. This removes most of the seasonal cycle and restricts the analysis to the monthly anomalies. The zonal mean was removed from the streamfunction following Hsu and Lin (1992). They found that the $250 \mathrm{hPa}$ streamfunction calculated from the ECMWF analyses contained a large symmetric component that obscured the global teleconnection pattern that they were studying. Preliminary analysis with the data used here also indicated that the removal of the zonal mean was important to reveal the details of the global response.

The National Meteorological Center (NMC) unintialized operational analyses are used for verification and comparison to the GCM output. These data have significant problems in that the changing data assimilations systems and observational networks introduce a bogus component to the low frequency variability. There is also a problem in analyses over the data-sparse tropics, that is particularly severe for the divergent component of the wind. A major change in the NMC global data assimilation system in May 1986 introduced a discontinuity in the divergent component. These problems with the NMC analyses are comprehensively documented by Trenberth and Olson (1988). In order to perform a completely parallel analysis between the NMC observed data and the AMIP GCM output, the full 120 months of NMC data are used. As will be seen these data do provide some useful information but caution should be used in providing too fine an interpretation. In any case, for comparison Hoerling et al. (1992) provide climatologies of the divergence over the time period 1986 to 1989 , and these data will be cited for some aspects of the divergence comparison shown here.

\section{Principal and common principal component analysis procedures}

The spherical harmonic coefficients of the anomaly data were analyzed using the principal components routine PRIN from the IMSL (1990) subroutine library. There are 120 months of data available and there are 110 coefficients representing the deviations from the seasonal mean. These data were used to compute a covariance matrix for input into the PCA routine. The components were analyzed in the spherical harmonic domain. Traditionally, the PCA analyses have been carried out using gridpoint data, to which there are two possible drawbacks. First, meteorological data have strong spatial correlations and this conflicts with the assumption of independence of the data points. Second, the convergence of the meridians toward the poles means 
that for an equally spaced latitude, longitude grid the data near the poles are sampled at a substantially higher spatial frequency than the equatorial data. However, the spherical harmonics allow a compact and nominally independent representation of the data that also allows for accurate spatial filtering and computation of derivatives. Since the spherical harmonics are eigenfunctions of the Laplacian on a sphere, the divergence and vorticity can be computed simply and accurately from the velocity potential and streamfunction, respectively. The spherical harmonic approach therefore appears to be useful when considering global data analysis.

The CPC technique is comprehensively described by Flury (1988). One of the main objectives in traditional principal component analysis is to find a coordinate system in which the representation of the say $p$ components of a multivariate vector are uncorrelated. In the search for a common covariance structure it is then natural to ask if it is possible to find a coordinate system in which the $p$ variables are uncorrelated, not only in one field but in two (or several ) fields simultaneously. One advantage in using the CPC model is that one can directly compare corresponding principal components. In addition, one can test the hypotheses of (partial) commonality of the principal axes of representation of two (or several) fields of data. It should be noted here that the application of the tests of significance ( as outlined by Flury, 1988 ) requires that the sample fields (over discrete time instants) be independent. This is in most cases not a valid assumption since fields over successive time instants are in fact correlated. This problem, however, does not preclude the use of common principal components as a diagnostic tool for understanding the commonality of the fields without a formal test of significance. It should be pointed out that the current use of EOFs for intercomparison does not usually go much beyond a visual comparison of the fields. It will also be shown that the CPC approach may be a useful means of interpreting the output for ensembles of GCM integrations using a single model, as well as comparing the output of many models. Previously, Frankigoul et al. (1995) have used the CPC methodology to intercompare the results of four models of the oceanic circulation. Their work is parallel to the study of the atmospheric models presented here.

A technique with a similar goal to CPC was first advocated by Kutzbach (1967), and was referred to as combined principal components (CPCA) by Bretherton et al. (1992). The CPCA technique takes all the data for two sources and combines them into a single covariance matrix, and then applies the principal component analysis to 
this matrix. The CPC technique, on the other hand, makes use of the separate covariance matrices. By maintaining this distinction, one is able to quantitatively intercompare the statistics of each of the data sets. The CPC is also capable of dealing with an arbitrary number of data sets. Bretherton et al. (1992) focussed on the problem of coupled patterns and thus only needed to consider two data sets.

In the present study the CPC analysis was carried out using an algorithm that produced results identical to the KPRINC routine from the IMSL (1991) library. In contrast to the PCs, there is a certain degree of arbitrariness to the ordering of the CPCs. The PCs can be ordered on the basis of the eigenvalues of the single covariance matrix, while in the case of the CPCs there are a number of covariance matrices. In this paper, a practical approach was adopted in that the CPC ordering was determined by the vector that had the largest values for a majority of the models. The result of this definition is that a component that is referred to as the first might not necessarily be the first for an individual model. We shall endeavor to be as clear as possible as to the nature of the ordering in the text to avoid any misunderstanding.

The CPC techniques use the exact same covariance matrices as the PC procedures. The fit that is undertaken here is in the spatial domain, thus there are some 31 distinct time series of the CPC ( 30 models + observations ) for each common vector or spatial field.

\section{Velocity potential results}

Since there are 30 models, and potentially 110 principal components, only a select subset of the analysis can be shown. Generally we will discuss only the leading components that have a physical interpretation.

\section{a. Principal components}

Figure 1 depicts the percent variance explained by the leading three principal component (PC) modes for the $200 \mathrm{hPa}$ velocity potential for the 30 models ( see Table 1 ) and for the NMC analyses. The degree of dominance of the first mode varies substantially among the models. Figure 2 contains plots of the time series of the principal components for the leading three component vectors for the models and the NMC analyses. As is obvious, the intent of Fig. 2 and subsequent similar figures is not to follow any particular model in detail but to gain an overall impression of all the mod- 
els' behavior. Figure 3 is a plot of the Climate Analysis Center (CAC) Southern Oscillation Index (SOI) for the same period as in Fig. 2. This index is based on the normalized sea level pressure difference between Darwin and Tahiti. Comparison of the leading PCs, Fig. 2a, and the SOI, Fig. 3, suggests that the first PC in both the models and NMC analyses has a signal consistent with the ENSO variations for this decade. Although in Fig. 2a the overall envelope of the ENSO/SOI signal is apparent, the models are by no means in lockstep. There is variation in the details of the phasing and amplitude of this first mode. From Fig. 1 it can be seen that the importance of the first mode varies substantially across the models accounting for 53\% to $18 \%$ percent of the variance explained. The corresponding value is $46 \%$ for the NMC analyses, although this figure must be viewed with some circumspection due to the well documented problems with the analyzed divergent wind. The first mode is dominant in some models, such as BMRC, NRL, CNRM and CCC, but somewhat less so in others, such as GLA, NCAR and NMC. This indicates a fairly large range of response in terms of this measure to the imposed SST variations. There is also quite a bit of variation with respect to the separation between the components as seen in Fig 1. BMRC has a clear distinction between the three components while NCAR and NMC have the first and second components almost equal. Thus there is not only a difference in the magnitude but also in the partitioning of the variance among the models. The second PC, Fig. 2b, also shows some influence of the extraordinary 82/83 ENSO event but the response is rather uneven. In general, for this mode there is very little relation amongst the models outside of the ENSO period of 82/83 and the end of the decade, which was a cold event for the tropical Pacific SST. Figure 2c, the third PC, shows a dropoff of amplitude, but the $82 / 83$ event is still in evidence; this mode generally accounts for less than $10 \%$ of the variance.

Figure 4 shows the correlation coefficient between the first three $\mathrm{PC}$ modes of the models and the SOI of Fig. 3. This chart is an attempt to quantify the relationship of the various PC modes to the ENSO cycle. As might be expected from Fig. 2a there is generally a good correlation between the SOI and the leading PC; twenty of the models have a correlation exceeding 0.5 for the leading component, corresponding to a significance level of $95 \%$ for 12 degrees of freedom. Some models have their greatest correlations with PCs other than the first. As seen in Figs. 1 and 2, the importance of the PCs declines quickly beyond the first two vectors so generally these higher components are of secondary importance in describing the spatial patterns of the diver- 
gent flow.

Figure 5 displays the principal vectors corresponding to the principal components in Fig. 2 for selected data sets. The Laplacian operator has been applied to the spherical harmonic coefficients of the velocity potential to yield the divergence pattern. The divergence exhibits a great deal more detail than the velocity potential and is the quantity that is directly linked, at least in the tropics, to variations in the diabatic heating. Presentation of all the 31 fields is not practical, so certain fields will be chosen to illustrate selected points.

Figure 5a is the first EOF for the NMC analyses. The pattern is the type documented for the mature phase of an El Nino episode, a prominent east-west dipole of deviations in the Equatorial Pacific with enhanced divergence over the mid-Pacific during ENSO events, (Hoerling et al. 1992 and Boer 1989). The pattern in the tropical western Pacific also resembles that of the first EOF of the precipitation data of Lau and Sheu (1991), which they associate with the ENSO cycle. All the models generally have some elements of this west Pacific dipole in the first EOF.

Figure $5 \mathrm{~b}$ is the first EOF for the CCC model. Figure 1 shows that for this model, this mode is dominant and explains $48 \%$ of the variance. The structure is fairly typical although other models tend to have a bit more structure, especially in the subtropics and midlatitudes, than the CCC model. The dipole of divergence anomaly is centered east of $150 \mathrm{E}$, while many models have a convergence center just west of the dateline along the Equator, farther east than in the analyses. The SUNYA (CCM1) model is presented in Fig. 5c. The large center at $30 \mathrm{~N}$, 90E seen in Fig. 5c shows up as a distinct feature in five of the AMIP models. This feature is most probably an artifact of the interpolation to pressure coordinates in the region of the Tibetan Plateau. The SUNYA model has more structure overall and more amplitude in the extratropics than the CCC model and NMC analyses. The MPI model, Fig. 5d, has a somewhat different pattern from the majority of the models in that the center of the dipole is shifted far to the west. The GSF model has a similar structure to that of the MPI model.

Figure 6 consists of plots of the second EOFs for same data as in Fig. 5. The time variations of the PCs, Fig. $2 \mathrm{~b}$, do not lend themselves to any obvious interpretation, beyond some impact of the $82 / 83$ event and the cold event at the end of the decade. Figure 6a shows the spatial divergence field of EOF 2 for the NMC analyses. Generally this field resembles the positions of the climatological mean maxima and minima and the EOF could be interpreted as interannual variations about this mean. The 
models tend to have a bit more amplitude than the analyses for the second EOF. The MPI EOF of Fig. 6d is more like the ENSO response which is consistent with its time series. It appears as though the MPI PCs do not separate the ENSO type mode as cleanly as they do in the other models and in the analyses. In this sense the modes are degenerate and perhaps some form of rotated PC procedures would alleviate this problem. This was not done since the purpose here is intercomparison and it was desired to keep the procedures as uniform as possible across the models.

The variations in the type and magnitude of the PC modes make a systematic comparison difficult. It is rather obvious that the common SST forcing does not dictate a lockstep in the low frequency response of the models. The PC results give the impression that the models have an underlying similarity to the observations and to each other during the ENSO events, but it is difficult to fully assess the degree of similarity due to the variability between the individual models. One must be careful in comparing the corresponding EOFs since they are a purely mathematical fit and do not contain any information about the physical mechanisms that produce them. As indicated by the MPI model, the first few EOFs for the models apparently do not necessarily encompass all the same physical phenomena. To address the comparison problem, the results of common principal components are now introduced.

\section{b. Common principal component analysis}

Figure 7 presents the CPC percent variance explained for the models for the 200 $\mathrm{hPa}$ velocity potential, analogous to the $\mathrm{PC}$ data in Figure 1. It is important to realize that in Figure 7 the variance explained does not refer to distinct components but to a common set of components across all the models. The ordering of the components is based on the ordering for the NMC analyses. For this variable, the models all share the same leading four components although the ordering does vary from model to model.

Comparing the values of variance explained in Figures 1 and 7 , it can be seen that the same models are the top three and bottom three in terms of variance explained for the leading vector. It should be anticipated that the variance explained will fall in going to the CPC representation since the PC performs the best fit for an individual data set and the CPC technique is a compromise fit across all the models. The NMC analyses demonstrate the expected decrease with a relatively modest change in going from the $\mathrm{PC}$ to the $\mathrm{CPC}$ representation. This indicates a stable refer- 
ence and also that the common structure found by the procedure has some basis in reality. Although the first two CPCs are generally dominant, there are models which reverse the ordering of the first two. Some of the second EOFs have increased as the first have fallen in going from the PC to CPC representation, as the variance explained amongst the modes is slightly re-partitioned.

Figure 8 displays the time series for three CPCs of the models. The time series of the CPC 1, Fig. 8a, would imply a similar correspondence to the CAC SOI in Fig. 3 as seen for most of the leading PCs. In general there is a better agreement between the models in Fig. 8a than in Fig. 2a. Figure 9 presents the correlation coefficients between the SOI and the first two CPCs for all the models and the NMC analysis. As in the PC analysis, there is generally a good correlation between the first CPC and the SOI, although for some models the correlation is better with the second CPC.

Figure 10 presents the EOF of the leading two CPCs. Note that although there are 31 curves in Fig. 8, there is only a single EOF since the CPC analyses was carried out in the spatial dimension and results in a common spatial pattern. Figure 10a appears to correspond in the tropics to an ENSO anomaly pattern with a dipole oriented east-west near 150E. Figure 10a illustrates how the CPC fits a common vector which possesses elements of all the models. For example, the divergence dipole of Fig. 5a, CCC, is evident in Fig. 10a as is the feature at $90 \mathrm{E}, 30 \mathrm{~N}$ which is in Fig. $5 \mathrm{~b}$ for the SUN model. Notice that there is a suggestion of a wavetrain emanating from the divergence center at the Equator near the dateline and arching northeastward toward North America. The second CPC, Fig. 10b, might also be interpreted as the interannual variation of the climatological divergence pattern as in the $\mathrm{PC}$ analysis.

In the next section attention shifts to the rotational component of the flow and to the presentation of results of the streamfunction analysis.

\section{Streamfunction}

This section will describe the pertinent results of the principal components and common principal component analysis for the $200 \mathrm{hPa}$ streamfunction.

\section{a. Principal component analysis}

The percent variance explained by the leading three PCs of the $200 \mathrm{hPa}$ streamfunction for the AMIP models and the NMC analyses is presented in Figure 11. There 
is a sharp drop in the amount of variance explained in going from the velocity potential to the streamfunction. There is a large variation in the explained variance from $23 \%$ to $8 \%$. However, to a large extent the relative rankings which the models had in the velocity potential analysis for the first component are retained in the streamfunction results. One might expect the velocity potential to be better described for the large-scale , monthly averaged inter-annual variations for two reasons . First, the velocity potential is generally dominated by larger space scales, and is well described by wavenumbers 1 to 3 , while the streamfunction tends to have more structure. Second, the velocity potential variations are dominated by the slowly changing forcing dictated by the tropical SST, while the streamfunction has a more prominent chaotic, midlatitude component. For the streamfunction data the NMC analyses might be more reliable than the velocity potential, since the rotational wind is generally considered to be better represented in the analyses than the divergent wind.

Figure 12 presents the time series of the first three PCs for the streamfunction for the AMIP models and the NMC analyses. As in the velocity potential results, there is a signal consistent with the SOI variations over the time period. Although there is a clear overall envelope for the curves in Fig. 12a, the leading PC, there is substantial variation in amplitude and phase. The second PC, Fig. 13b, indicates only modest model agreement near the time of the 82/83 ENSO and at the end of the decade. In the third PC (Fig. 12a), there is virtually no correlation. The amount of variance explained by this last PC is small, generally on the order of $5 \%$. Figure 13 confirms the impression of a consistent ENSO signal by showing that the correlation between the SOI and the leading PC for the models exceeds 0.5 for 21 of the models. The value is 0.75 for the analyses, which is greater than that of any of the models. In some models the second PC has a better correlation with the SOI.

Figure 14a shows the leading principal vector of the NMC analyses. As might be expected from the time series, the leading vector for the NMC data (Fig. 14a) is characteristic of the ENSO anomaly patterns, especially the 82/83 event (Rasmussen, 1991). The twin gyres on either side of the Equator east of the dateline are a consistent ENSO signature. Note that there is some indication of a wavetrain propagating poleward from the mid-Pacific. All the models display some form of the basic ENStype structure, although there are variations in position and intensity of the Pacific gyres and the analogous PC is not always the leading PC. There is a dynamical consistency in that the equatorial gyres are usually located just to the east of the diver- 
gence anomalies shown by Fig. 5. As indicated by Fig. 13, this ENSO signature is not the leading feature for a number of models, of which JMA, NMC and GSFC are examples. The MPI model has the first two modes of almost equal magnitude, and, as in the velocity potential, an ENSO-type mode is not clearly isolated by this simple PC analysis for this model.

The CCC model (Fig. 14b) shows the dipole straddling the equator but with a longitudinal shift in position of about 20 degrees west with respect to the observations. The leading mode for the SUNYA model (Fig 14c) reproduces the response of the analyses fairly well, especially in the tropics and sub-tropics. The first EOF for the MPI model (Fig. 14d) does not have the ENSO signature, and resembles the second EOF of the analyses. The second EOF for the NMC analysis (Fig. 15a) bears a fair resemblance to the climatological standing wave pattern, and could be interpreted as the variation in the climatological mean features as in the case of the corresponding EOF in the divergence.

There is such a diversity in the patterns displayed by the models that it is not fruitful to pursue the details of the comparisons here. Before going on to the CPC streamfunction results, however, it is useful to point out that the common patterns cited by past studies, such as the PNA are seen in many of the EOF fields. The amount of variance explained by the PNA-type patterns is generally about 6\%. Since this pattern is usually identified with the northern hemisphere winter in a specific region, it is not surprising that it has a small explained variance in the global annual data set.

\section{b. Common principal component results}

Figure 16 summarizes the results of the CPC analysis for the streamfunction in terms of percent variance explained. As in the velocity potential results, the overall level of the explained variance drops in comparison to Fig. 11, the PC variance explained. In the figure the values for only two CPCs are shown; these are the only two that are among the leading four of each model and are the leading two of the analyses. These two components maintain about the same level in the PC and CPC for the analyses, as was the case in the velocity potential. No mode explains a large part of the variance and even the modest amount of the first component drops off rapidly.

Figure 17 displays the time series of the CPC analysis. The first mode is the one explaining the most variance in all but one of the models (GSF), while the second is either the first or second for all but two of the models (NCA and NMC). Figure 17a 
clearly indicates that this mode corresponds to the ENSO oscillations, with an increase in the agreement between all the models. As seen in Fig. 18, the correlation between the SOI and the curves in Fig. 17a, all but two of the models have correlations above 0.5 . The second CPC, Fig. 17b, shows the influence of the ENSO events but the overall correlation between the simulations is reduced relative to the first CPC.

Figure 19 shows the EOFs of the two CPCs. The first pattern, Fig. 19a, is much like that of the analyses, and has the ENSO signature in the tropics. There is a hint of a wavetrain arching over North America originating from the tropical dateline. The second pattern (Fig. 19b) is reminiscent of those produced by GCMs with no external boundary variations and thus may represent an oscillation with an internal source (Branstator, 1992, Metz, 1994). Figure 19c shows a CPC with a distinctive PNA-type pattern, although this mode generally accounts for less than $6 \%$ of the variance.

\section{Sensitivity of the ECMWF AMIP model}

A fact that must be acknowledged is that the foregoing analyses are all based on single integrations of each model. The intrinsic variability of the dynamical system which they simulate means that other integrations of the same model using slightly different initial conditions will yield different results. There is therefore a need to ascertain the significance of the differences seen in the CPC and PC analyses presented above compared to the intrinsic variability of each model. To address this issue, the same calculations were carried out for a number of decadal integrations using the ECMWF AMIP model. Four additional AMIP runs were made with identical external forcing but with slightly different initial conditions. The initial conditions used were the ending points of the previous integration, resulting in an ensemble of five integrations. Tables 2 and 3 present the results of the $P C$ and CPC velocity potential analysis for this ensemble, while Figure 20 presents the CPCs of the 5 integrations for components 1 to 4 . The type of variation seen in this figure between the simulations is representative of the $\mathrm{PC}$ of the velocity potential and the CPC and $\mathrm{PC}$ analyses of the streamfunction. The changes in percent variance explained in going from the $\mathrm{PC}$ to CPC representation for the ensemble data are generally smaller than the intermodel changes. The differences between runs seen in Table 2 is as great as $7 \%$ for the first component. In Tables 4 and 5,for the streamfunction, the second and third vectors ex- 
plain about the same amount of variance. In one realization the ordering of these vectors was reversed (ECM-4), but the difference in the variance explained is not large. The ordering of the dominant distinct vectors remains intact throughout all the realizations. The differences between realizations are generally smaller than the differences between the models, and the interpretation of the components is consistent across the ensemble. In order to generalize these results from a specific model, it must be assumed that the other models would behave in a similar fashion over an ensemble of integrations. These ensemble results indicate the folly of putting a fine interpretation on small differences among single integrations of the models.

\section{Discussion and conclusions}

The models respond similarly and strongly to the specified SST fields in their divergence field, but correspondence is less prominently reflected in the streamfunction. This is due to the fact that the divergence response has its largest magnitude in the tropics, whilst the streamfunction has a large response in the extratropics. As shown by Boer (1989), the tropical response in more nearly linear than the extratropical response. This is due to the non-linear nature of the equatorial response to a divergence forcing and to the chaotic nature of the midlatitude dynamics in which the streamfunction deviations have a large amplitude and are not strongly influenced by the specified SST. The extratropical variations have an internal source that depends on the basic state and its interactions with low and high frequency transients. Given a specified SST the models yield a surprising amount of agreement in the divergence field. However, the global vorticity dynamics give emphasis to the non-linear nature of the climate response and would indicate that the statistics of a ten year integration are insufficient to define the envelope of the climate influenced by the changing SST. Note that the years $82 / 83$ and $86 / 87$ were among the strongest SST anomalies and the agreement found here might not be present in another decade. An encouraging sign is that the consensus view more closely resembles the observations than most individual models. The model outliers that do not agree with the consensus are also at variance with the observations.

The chief purpose of the PC analyses is to reduce the description of the data to its most parsimonious representation. For model intercomparison the CPC methodology enables the description to occupy the same reduced parameter space across all the 
models. All the models share the same two leading CPC for the velocity potential field, and these two modes are dominant in that they account for more than $50 \%$ of the variance for virtually all of the models. Thus a parameter space formed by these two modes will form a rather minimal dynamical subspace to examine the models' behavior. Kimoto and Ghil (1993) plotted the distribution of 37 years of the observed 700 $\mathrm{mb}$ height anomalies on a bivariate chart using the leading two EOFs of the anomalies. This provided insight into the dynamics of the persistent modes they were examining. Figure 21a is a plot of the positions of the 120 months of NMC analyses in a domain defined by the leading two CPCs of the velocity potential. The points designated by the stars are times when the SOI of Fig. 3 is above 0.5 (cold events) and the filled circles are times when it is below -0.5 (warm events). This is done to emphasize the impact of the ENSO cycles on the trajectory of the models in this space. The contours are computed using a kernel density estimator (Silverman, 1986). A simple gaussian kernel was used with a window width of 1.0. The plotted data points were scaled using the standard deviation of the times series for each CPC, such that the resulting contours would be concentric circles if the probability of being in either state was equal. The contours are referred to as probability density functions (PDF) by Cheng and Wallace ( 1993) and Kimoto and Gill (1993). The PDF (Fig. 21a) for the analyses are fairly circular about the origin. As should be expected from CPC time series, there is a distinct partitioning of the two ENSO states about the CPC 1 axis. On the other hand, CPC2 appears to be somewhat insensitive to the overall ENSO cycle.

Figures $21 \mathrm{~b}$ and $21 \mathrm{c}$ display the PDF diagrams for the velocity potential CPCs for the CSU and DERF models, respectively. These were chosen since they represent two models that are extremes in terms of the PDF distribution. CSU occupies a somewhat smaller domain in this space than does the DERF model. The latter model is considerably more active in terms of the interannual variations. Both models maintain about the same distinction of the ENSO cycle with respect to the sign of CPC 1 as do the observations. The CSU PDF forms almost concentric rings about the origin while DERF has more structure and two maxima on either side of the CPC 2 zero line. Kimoto and Ghil (1993) and Cheng and Wallace(1993) perform statistical significance tests of the deformations of the PDF. Unfortunately, there are not enough data available in the present time series to compute any meaningful statistics, although the models represent an almost continuous spectrum between the extremes represented by Figs. 21b and 21c. The GLA model PDF (Fig. 21d), shows an extreme distortion 
about the CPC 1 axis.

Figure 22 is a plot of the median distance of the points from the origin for the PDF diagrams for all the models and for the observations. This is meant as a simple alternative for presenting 31 figures and provides a measure of the spread of the variability in this dynamical space. The results indicate that the only consistent grouping is among the models that are closely related to the UCLA model (CSU, UCLA, MRI, YONU), which consistently occupy a relatively smaller dynamic domain than the other models. The other two models near the bottom (UIUC and IAP) also share similar surface schemes and have some of these aspects in common with YONU. Both the CSU and GLA models use some variant of the Arakawa-Schubert convective closure, while the UCLA cousin models all use a similar is the PBL formulation (Phillips, 1994).

Two models which share almost all characteristics save the convective scheme are UGAMP and ECMWF. The ECMWF model uses the Tiedtke mass flux closure while the UGAMP model uses the Betts-Miller convective adjustment scheme. The MPI models is also very closely related to the ECMWF model. (The MPI model originated from the ECMWF and still shares many of the same parameterizations, but numerous changes were made in the model to make it more suitable for long term climate simulations.) The PDFs of these three models are shown in Fig. 23(a,b,c). The values of the ECMWF and UGAMP models are closer to each other than either is to MPI; this would imply that the convective parameterization need not have an overwhelming impact on the models response to the SST. The relaxing of some of the specifications of the land surface evidently permits the MPI model to display more variability. Figure $23 \mathrm{~d}$ is the $\mathrm{PDF}$ for one of the members of the ensemble of five integrations of the ECMWF GCM. This shows the danger of interpreting any of the lobes of the PDF from this small sample. Although the median distance is robust across the ensemble, the shapes shown in Figs. 23a and 23d are different. It will take a somewhat longer integration to establish significant asymmetries in the PDF.

Given these differences in the interannual variation one obvious root cause might be the model response in the precipitation field to the variations of SST, particularly in the tropics. Table 6 presents the linear correlation coefficient and the linear slope between the deviations in SST and precipitation for the ENSO 4 region (160E-150E, 5N-5S) for all the models that have these fields available. There is a wide variation in the correlation and model sensitivity as represented by the slope. A sim- 
ple minded approach might give rise to the hypothesis that models with a large correlation in Table 2 would have a large explained variance in Figs. 1 , 7, 11 and 16. Or that a large sensitivity between the SST and precipitation would lead to a model occupying a larger portion of the PDF space. Neither of these relations are indicated by the data. The reason why a model behaves as it does goes beyond just the convective scheme or resolution, and involves a synergy between all the elements of its formulation. More detailed and extensive AMIP-type experiments will be required to explain model differences.

Palmer(1993) proposes a partition of the GCM uncertainty into two types. The first is the intrinsic variability and sensitivity to initial conditions which is typical of the non-linear dynamical system that the models simulate. This is illustrated in the sensitivity integrations. The second type is the uncertainty in the formulation of the physics of the model. This is addressed partially by the AMIP results, in which models with different parameterizations are run with identical external forcing, although the initial conditions vary. The data give at least some indication that the second uncertainty might be the dominant one at the present state of modeling. This is good news, since presumably as our knowledge progresses and computers become more powerful this uncertainty can be reduced until one comes up against the inherent limitations of the problem.

It would appear to be a vital area of research to resolve these differences before embarking on an extensive program of modeling with a coupled, interactive atmosphere and ocean model.

Acknowledgments. The cooperation of the ECMWF in making their forecast model available and in providing expert technical advice for this research is gratefully acknowledged. The generosity of the modeling groups involved in AMIP in making their results available is greatly appreciated. This work was performed under the auspices of the Department of Energy Environmental Sciences Division by the Lawrence Livermore National Laboratory under contract W-7405-ENG-48. 


\section{References}

Barnston, A. G., and R. F. Livezey, 1987: Classification, seasonality and persistence of low-frequency atmospheric circulation patterns. Mon. Wea. Rev., 115, 10831126.

Boer, G. J., 1985: Modeling the atmospheric response to the 1982/83 El Nino. Proc. 16th Int. Liege Colloq. on Ocean Hydrodynamics. Chap. 2., Elsevier Oceanography Series, 767pp.

Boer, G. J., 1989: Concerning the response of the atmosphere to a tropical sea surface temperature anomaly. J. Atmos. Sci., 46, 1898-1921.

Bjerknes, J., 1969: Atmospheric teleconnections from the equatorial Pacific. Mon. Wea. Rev, 97, 501-510.

Blackmon, M. L., Geisler, J. E., and E. J. Pitcher, 1983: A general circulation model study of January climate anomaly associated with interannual variations of equatorial Pacific sea surface temperatures. J. Atmos. Sci., 40, 1410-1425.

Branstator, G., 1990: Low-frequency patterns induced by stationary waves. J. Atmos. Sci., 47, 629-648.

Branstator, G., 1992: The maintenance of low-frequency anomalies., J. Atmos. Sci., 48, 1924-1945.

Bretherton, C. S., C. Smith, and J. M. Wallace, 1992: An intercomparison of methods for finding coupled patterns in climate data., J. Climate, 5, 541-560.

Cheng, X., and J. M. Wallace, 1993: Cluster analysis of the northern hemisphere wintertime $500 \mathrm{hPa}$ height field: Spatial patterns. J. Atmos. Sci., 50, 2674-2696.

Flury, B., 1988: Common Principal Components and Related Multivariate Models, J. Wiley, New York, pp 258.

Frankigoul, C., S. Fevrier, N. Sennechael, J. Verbeek, and P. Braconnot, 1995: An intercomparison between four tropical ocean models: Thermocline variability. $\mathrm{Tel}$ lus, 47A, 351-364.

Gates, W. L., 1992: AMIP: The atmospheric model intercomparison project. Bull. Amer. Meteor. Soc., 73, 1962-1970.

Gill, A. E., 1980: Some simple solutions for heat-induced tropical circulation., Q. J. R. Meteorol. Soc., 106, 447-462. 
Hoerling, M. P., Blackmon, M. L., and M. Ting, 1992: Simulating the atmospheric response to the 1985-87 El Nino Cycle. J. Climate, 5, 669-682.

Hoerling, M. P., L. L. DeHaan, and J. W. Hurrel, 1993: Diagnosis and Sensitivity of the $200 \mathrm{hPa}$ Circulation in NCAR Community Climate Models. NCAR Technical Note, NCAR/TN-394+STR, National Center for Atmospheric Research, Boulder, $\mathrm{CO}, 68 \mathrm{pp}$.

Horel, J. D. and J. M. Wallace, 1981: Planetary-scale atmospheric phenomena associated with the southern oscillation. Mon. Wea. Rev., 109, 813-829.

Horel, J. D., 1981: a rotated principal component analysis of the interannual variability of the northern hemisphere $500 \mathrm{mb}$ height field. Mon. Wea. Rev., 109, 20802092.

Hoskins, B. J., and T:Ambrizzi, 1993: Rossby wave propagation on a realistic longitudinally varying flow. J. Atmos. Sci., 50, 1661-1671.

Hsu, H.-H., and S.-H. Lin, 1992: Global teleconnections in the 250-mb streamfunction field during the northern hemisphere winter. Mon. Wea. Rev., 120, 1169-190.

IMSL Stat/Library, 1991: IMSL Inc., Houston, 1578pp.

Kimoto, K., and M. Ghil, 1993: multiple flow regimes in the northern hemisphere winter. Part I: Methodology and hemispheric regimes. J. Atmos. Sci., 50, 2626-2643.

Kutzbach, J., 1967: Empirical eigenvectors of sea-level pressure, surface temperature and precipitation complexes over North America. J. Appl. Meteor., 6, 791-802.

Lau, K.-M., and P. J. Sheu, 1991: Teleconnections in global rainfall anomalies: seasonal to inter-decadal time scales. In Teleconnections Linking Worldwide Climate Anomalies, eds. M. H. Glantz, R. W. Katz and N. Nicholls, Cambridge University Press, 535 pp.

Lau, N-C., 1981: A diagnostic study of recurrent meteorological anomalies appearing in a 15 year simulation with a GFDL general circulation model. Mon. Wea. Rev., 109, 2287-2311.

Lau, N.-C., 1985: Modeling the seasonal dependence of the atmospheric response to observed El Ninos in 1962-76. Mon. Wea. Rev., 113, 1970-1996.

Lau, N.-C., and M. J. Nath, 1990: A general circulation model study of the atmospheric response to extratropical SST anomalies observed in 1950-79. J. Climate, 3, 965-989.

Lau, N.-C., 1993: Climate variability simulated in GCMs. In Climate System Modeling, Cambridge University Press, K. E. Trenberth (Ed.) , 617-642. 
MacVean, M. K., 1985: Long-wave growth by baroclinic processes. J. Atmos. Sci., 48, 1089-1101.

Metz, W., 1994: Singular modes and low-frequency atmospheric variability. J. Atmos. Sci., 51, 1740-1753.

Palmer, T. N., 1993: Extended-range atmospheric prediction and the Lorenz model. Bull. Am. Meteor. Soc., 74, 49-65.

Palmer, T. N., and D. A. Mansfield, 1986: A study of wintertime circulation anomalies during past EI Nino events using a high resolution general circulation model I: Influence of model climatology. Quart. J. Roy. Meteor. Soc., 112, 613-638.

Philander, S. G., 1990: El Nino, La Nina, and the Southern Oscillation, Academic Press, New York, 293pp.

Phillips, T., 1994: A summary documentation of the AMIP models. PCMDI Report No. 18, Program for Climate Model Diagnosis and Intercomparison, University of California, Lawrence Livermore National Laboratory, Livermore, CA, 300pp.

Rasmussen, E., 1991: Observational aspects of ENSO cycle teleconnections. Teleconnections linking worldwide climate anomalies. eds. M. H. Glantz, R. W. Katz and N. Nicholls, Cambridge University Press, Cambridge, pp 523.

Sengupta, S., and J. Boyle, 1994: Statistical intercomparison of global climate models: A common principal component approach. PCMDI Report No. 13, Program for Climate Model Diagnosis and Intercomparison, University of California, Lawrence Livermore National Laboratory, Livermore, CA, 41pp.

Shukla, J., and M. J. Fennessy, 1988: Numerical simulation of the atmospheric response to the time-varying El Nino SST anomalies during May 1982 through October 1983. J. Climate, 1, 195-211.

Silverman, B. W., 1986: Density Estimation for Statistics and Data Analysis, Chapman and Hall, London, 175pp.

Trenberth, K. E., and J. G. Olson, 1988: Evaluation of NMC Global Analysis: 19791987. NCAR/TN-299+STR, Climate and Global Dynamics Division, NCAR, Boulder, CO, 82pp.

Tribbia, 1991: The rudimentary theory of atmospheric teleconnections. Teleconnections linking worldwide climate anomalies. eds. M. H. Glantz, R. W. Katz and N. Nicholls, Cambridge University Press, Cambridge, pp 523. 
Wallace, J. M., and M. L. Blackmon, 1983: Observations of low-frequency atmospheric variability. In Large-Scale Dynamical Processes in the Atmosphere, Academic Press, B. J. Hoskins and R. P. Pearce (Eds.), 55-94.

Wallace, J. M., and D. S. Gutzler, 1981: Teleconnections in the geopotential height field during the northern hemisphere winter. Mon. Wea. Rev., 109, 784-812. 
Table 1. The AMIP models used in this study and some aspects of their spatial resolution. Table taken from Phillips (1994), where a comprehensive description of each model is given.

\begin{tabular}{|c|c|c|c|c|c|}
\hline \multirow{2}{*}{ AMUP Model } & \multicolumn{2}{|c|}{ Horizontal } & \multicolumn{3}{|c|}{ Vertical } \\
\hline & Representation & Resolution & Coordinates & No. Levels & Bottom, Top \\
\hline BMRC & spectral & rhomboidal 31 & sigma & $9(3,3)$ & $991,9 \mathrm{hPa}$ \\
\hline$\overline{\mathrm{CCC}}$ & spectral & triangular 32 & hybrid & $10(3,4)$ & $980,5 \mathrm{hPa}$ \\
\hline CNRM & spectral & triangular 42 & hybrid & $30(4,20)$ & $995,0.01 \mathrm{hPa}$ \\
\hline$\overline{\text { COLA }}$ & spectral & rhomboidal 40 & sigma & $18(5,4)$ & $995,10 \mathrm{hPa}$ \\
\hline CSIRO & spectral & rhomboidal 21 & sigma & $9(3,3)$ & $979,21 \mathrm{hPa}$ \\
\hline CSU & finite difference & $4 \times 5$ degrees & modified sigma & $17(2,6)$ & variable, $51 \mathrm{hPa}$ \\
\hline DERF & spectral & triangular 42 & sigma & $18(5,5)$ & $998,2 \mathrm{hPa}$ \\
\hline$\overline{\mathrm{DNM}}$ & finite difference & $4 \times 5$ degrees & sigma & $7(1,1)$ & $929,71 \mathrm{hPa}$ \\
\hline ECMWF & spectral & triangular 42 & hybrid & $19(5,7)$ & $996,10 \mathrm{hPa}$ \\
\hline GFDL & spectral & rhomboidal 30 & sigma & $14(4,4)$ & $997,15 \mathrm{hPa}$ \\
\hline GISS & finite difference & $4 \times 5$ degrees & sigma & $9(2,2)$ & $975,10 \mathrm{hPa}$ \\
\hline GLA & finite difference & $4 \times 5$ degrees & sigma & $17(5,4)$ & $994,12 \mathrm{hPa}$ \\
\hline$\overline{\text { GSFC }}$ & finite difference & $4 \times 5$ degrees & sigma & $20(5,7)$ & $994,10 \mathrm{hPa}$ \\
\hline JMA & spectral & triangular 42 & hybrid & $21(6,7)$ & $995,10 \mathrm{hPa}$ \\
\hline LMD & finite difference & 50 sinlat $\times 64$ lon & sigma & $11(3,2)$ & $979,4 \mathrm{hPa}$ \\
\hline MGO & spectral & triangular 30 & sigma & $14(5,4)$ & $992,13 \mathrm{hPa}$ \\
\hline MPI & spectral & triangular 42 & hybrid & $19(5,7)$ & $996,10 \mathrm{hPa}$ \\
\hline$\overline{\text { MRI }}$ & finite difference & $4 \times 5$ degrees & hybrid & $15(1,9)$ & variable, $1 \mathrm{hPa}$ \\
\hline NCAR & spectral & triangular 42 & hybrid & $18(4,7)$ & $992,3 \mathrm{hPa}$ \\
\hline NMC & spectral & triangular 40 & sigma & $18(5,4)$ & $995,21 \mathrm{hPa}$ \\
\hline$\overline{\text { NRL }}$ & spectral & triangular 47 & hybrid & $18(5,5)$ & $995,1 \mathrm{hPa}$ \\
\hline SUNYA & spectral & rhomboidal 15 & sigma & $12(3,5)$ & $991,9 \mathrm{hPa}$ \\
\hline UCLA & finite difference & $4 \times 5$ degrees & modified sigma & $15(2,9)$ & variable, $1 \mathrm{hPa}$ \\
\hline UGAMP & spectral & triangular 42 & hybrid & $19(5,7)$ & $996,10 \mathrm{hPa}$ \\
\hline UIUC & finite difference & $4 \times 5$ degrees & sigma & $7(3,0)$ & $990,200 \mathrm{hPa}$ \\
\hline UKMO & finite difference & $2.5 \times 3.75$ degrees & hybrid & $19(4,7)$ & $997,5 \mathrm{hPa}$ \\
\hline
\end{tabular}


Table 2. Percent variance explained for the leading three principal components of the $200 \mathrm{hPa}$ velocity potential for five realizations of the ECMWF AMIP simulation.

\begin{tabular}{|c|c|c|c|}
\hline & PC 1 & PC 2 & PC 3 \\
\hline \hline ECM & 37 & 30 & 7 \\
\hline ECM-2 & 44 & 23 & 8 \\
\hline ECM-3 & 38 & 28 & 7 \\
\hline ECM-4 & 41 & 25 & 9 \\
\hline ECM-5 & 39 & 28 & 9 \\
\hline
\end{tabular}

Table 3. Percent variance explained for the leading three common principal components of the $200 \mathrm{hPa}$ velocity potential for e five realizations of the ECMWF AMIP simulation.

\begin{tabular}{|c|c|c|c|}
\hline & CPC 1 & CPC 2 & CPC3 \\
\hline \hline ECM & 37 & 31 & 7 \\
\hline ECM-2 & 43 & 24 & 8 \\
\hline ECM-3 & 38 & 28 & 7 \\
\hline ECM-4 & 41 & 25 & 9 \\
\hline ECM-5 & 39 & 28 & 9 \\
\hline
\end{tabular}


Table 4. Percent variance explained for the leading three principal components of the $200 \mathrm{hPa}$ streamfunction for the five realizations of the ECMWF AMIP simulation.

\begin{tabular}{|c|c|c|c|}
\hline & PC 1 & PC 2 & PC 3 \\
\hline \hline ECM & 16 & 10 & 6 \\
\hline ECM-2 & 18 & 8 & 8 \\
\hline ECM-3 & 19 & 7 & 7 \\
\hline ECM-4 & 17 & 9 & 7 \\
\hline ECM-5 & 17 & 10 & 7 \\
\hline
\end{tabular}

Table 5. Percent variance explained for the leading three common principal components of the $200 \mathrm{hPa}$ streamfunction for the five realizations of the ECMWF AMIP simulation, together with their standard deviation.

\begin{tabular}{|c|c|c|c|}
\hline & CPC 1 & CPC 2 & CPC 3 \\
\hline \hline ECM & 16 & 9 & 6 \\
\hline ECM-2 & 17 & 8 & 8 \\
\hline ECM-3 & 18 & 7 & 7 \\
\hline ECM-4 & 16 & 7 & 8 \\
\hline ECM-5 & 16 & 10 & 6 \\
\hline \hline std. dev. & 0.9 & 1.3 & 1.0 \\
\hline
\end{tabular}


Table 6. Linear correlation coefficient and slope of a linear fit of the interannual variations of SST and precipitation for the AMIP simulations.

\begin{tabular}{|l|l|l|}
\hline \multicolumn{1}{|c|}{ MODEL } & \multicolumn{1}{|c|}{ Correlation(ppt,SST) } & \multicolumn{1}{c|}{ Slope (mm/day/K) } \\
\hline \hline BMRC & 0.84 & 0.52 \\
\hline CCC & 0.88 & 0.61 \\
\hline CNRM & 0.86 & 0.51 \\
\hline COLA & not available & not available \\
\hline CSIRO & 0.93 & 0.53 \\
\hline CSU & 0.94 & 0.62 \\
\hline DERF & 0.84 & 0.39 \\
\hline DNM & 0.74 & 1.25 \\
\hline ECMWF & 0.84 & 0.39 \\
\hline GFDL & 0.74 & 0.45 \\
\hline GISS & 0.86 & 0.60 \\
\hline GLA & 0.85 & 0.36 \\
\hline GSFC & 0.72 & 0.70 \\
\hline LAP & 0.80 & 0.65 \\
\hline SMA & 0.89 & 0.45 \\
\hline LMD & 0.89 & 0.51 \\
\hline MGO & 0.65 & 0.57 \\
\hline MPI & 0.85 & 0.36 \\
\hline MRI & 0.81 & 0.84 \\
\hline NCAR & 0.80 & 0.33 \\
\hline NMC & 0.80 & 0.73 \\
\hline NRL & 0.86 & 0.50 \\
\hline RPN & 0.67 & 0.47 \\
\hline SUNYA & 0.64 & 0.45 \\
\hline SUNYA/G & 0.84 & 0.44 \\
\hline UCLA & 0.92 & 0.67 \\
\hline UGAMP & 0.82 & 0.33 \\
\hline UIUC & 0.92 & 0.97 \\
\hline UKMO & 0.81 & \\
\hline YONU & 0.35 \\
\hline & & \\
\hline & & \\
\hline
\end{tabular}




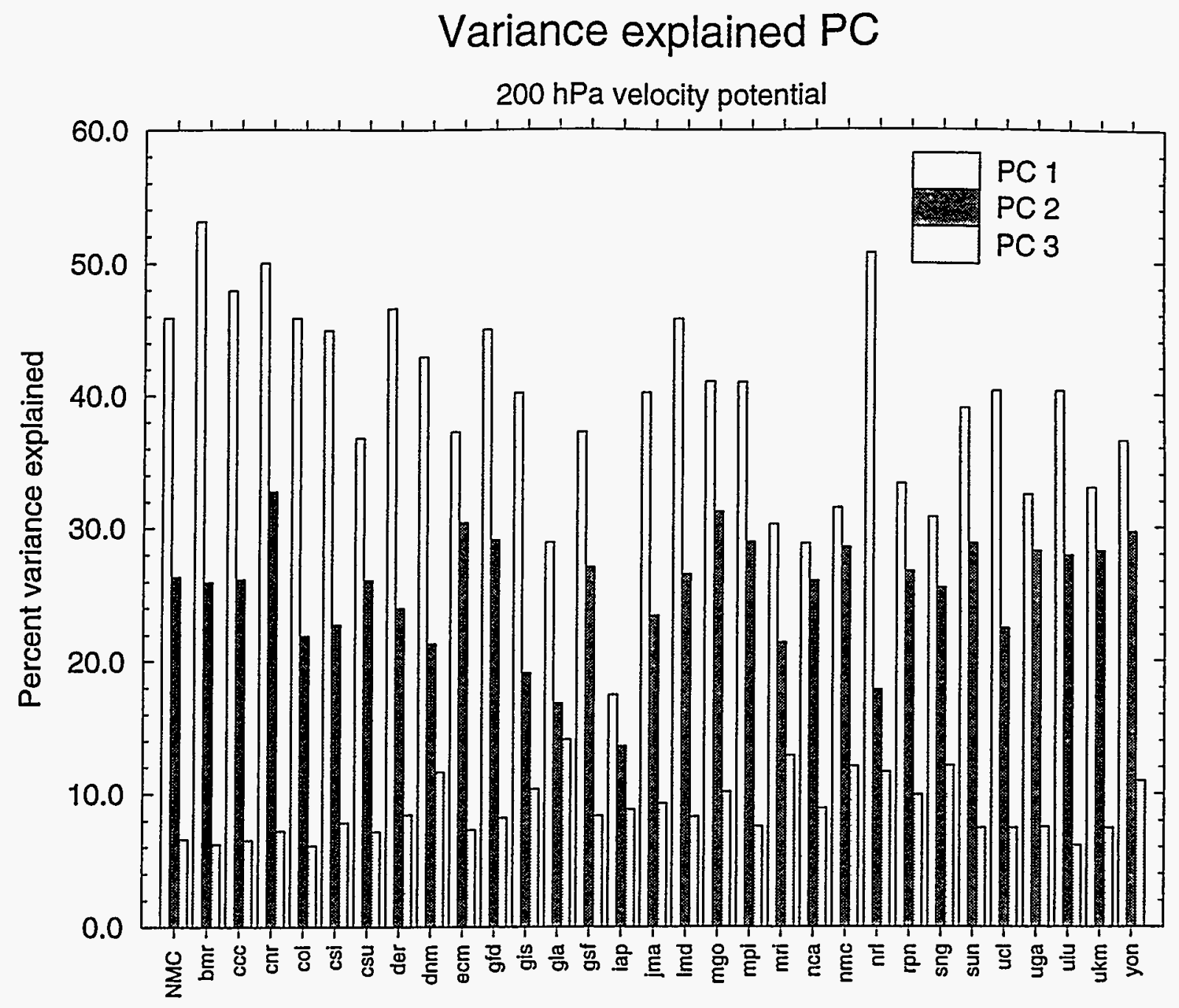

Figure 1. Bar chart of the percent variance explained by the leading three PCs for the $200 \mathrm{hPa}$ velocity potential for the AMIP simulations and NMC analysis. 
a

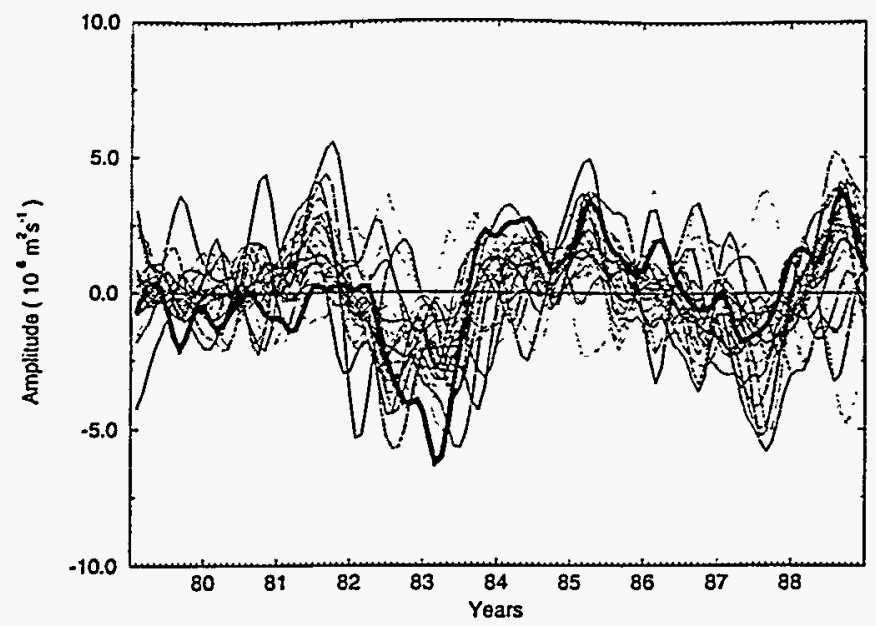

b
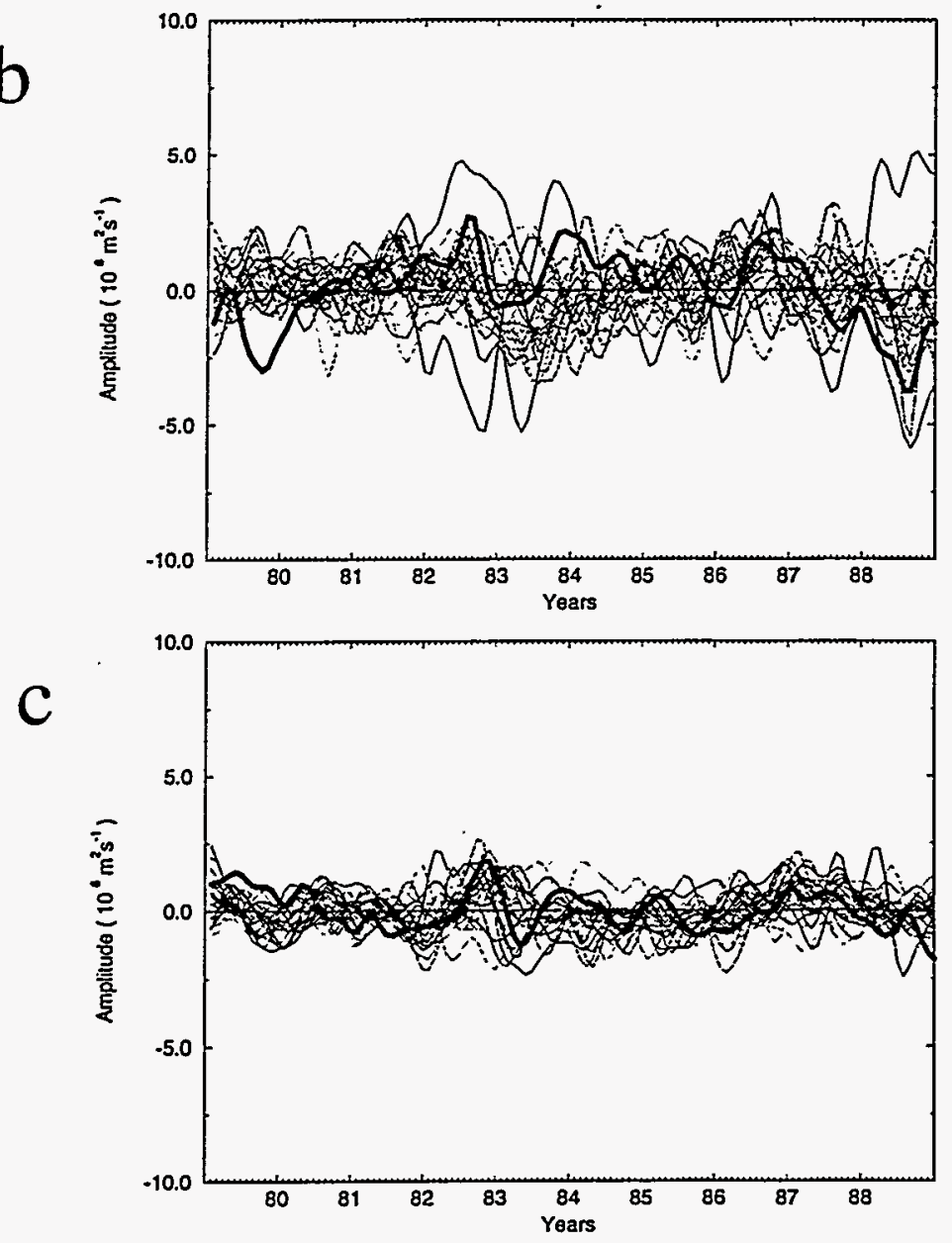

Figure 2. Time series of the principal components of the $200 \mathrm{hPa}$ velocity potential for the AMIP models and the NMC analysis. (a) First component, (b) second component, (c) third component. The thick line is the NMC analysis. 


\section{CAC SO Index}

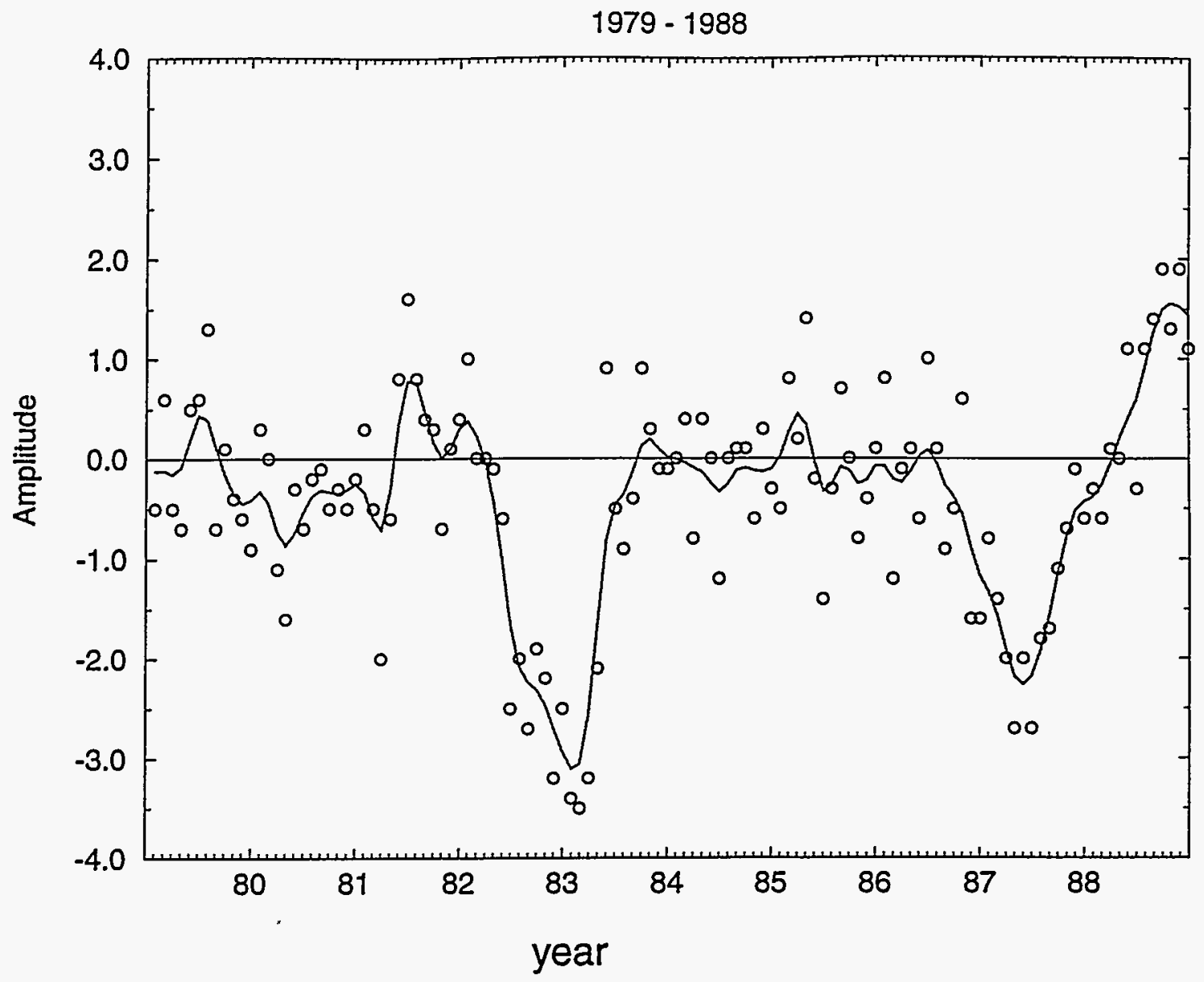

Figure 3. The Southern Oscillation Index (SOI) computed by the Climate Analysis Center for 1979 to 1988. The index is the normalized difference in monthly averaged MSL pressure between Darwin and Tahiti. 


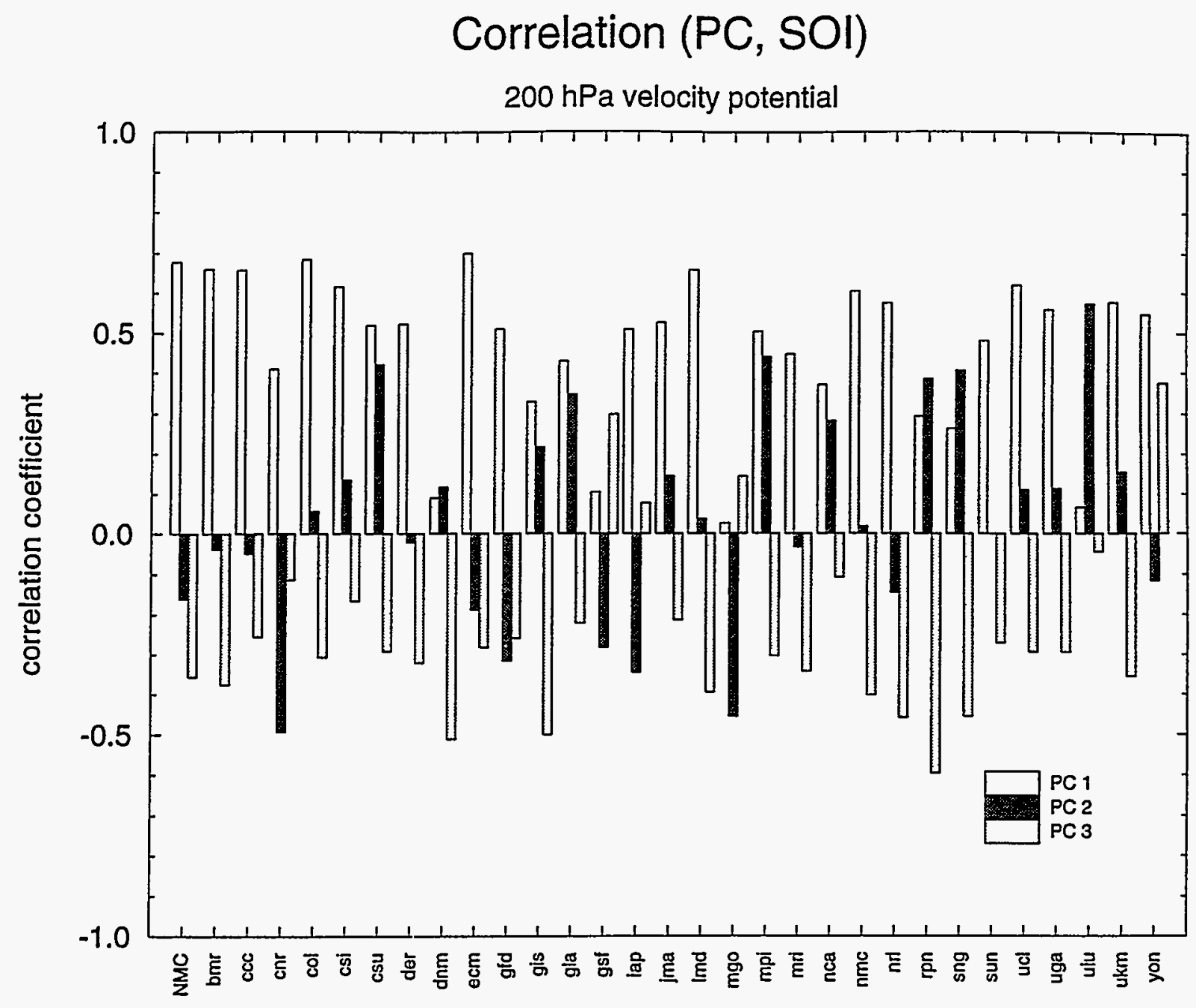

Figure 4. Bar chart of the linear correlation coefficient between the time series of the first three PCs for the $200 \mathrm{hPa}$ velocity potential, Fig. 2 , and the SOI, Fig. 3. 

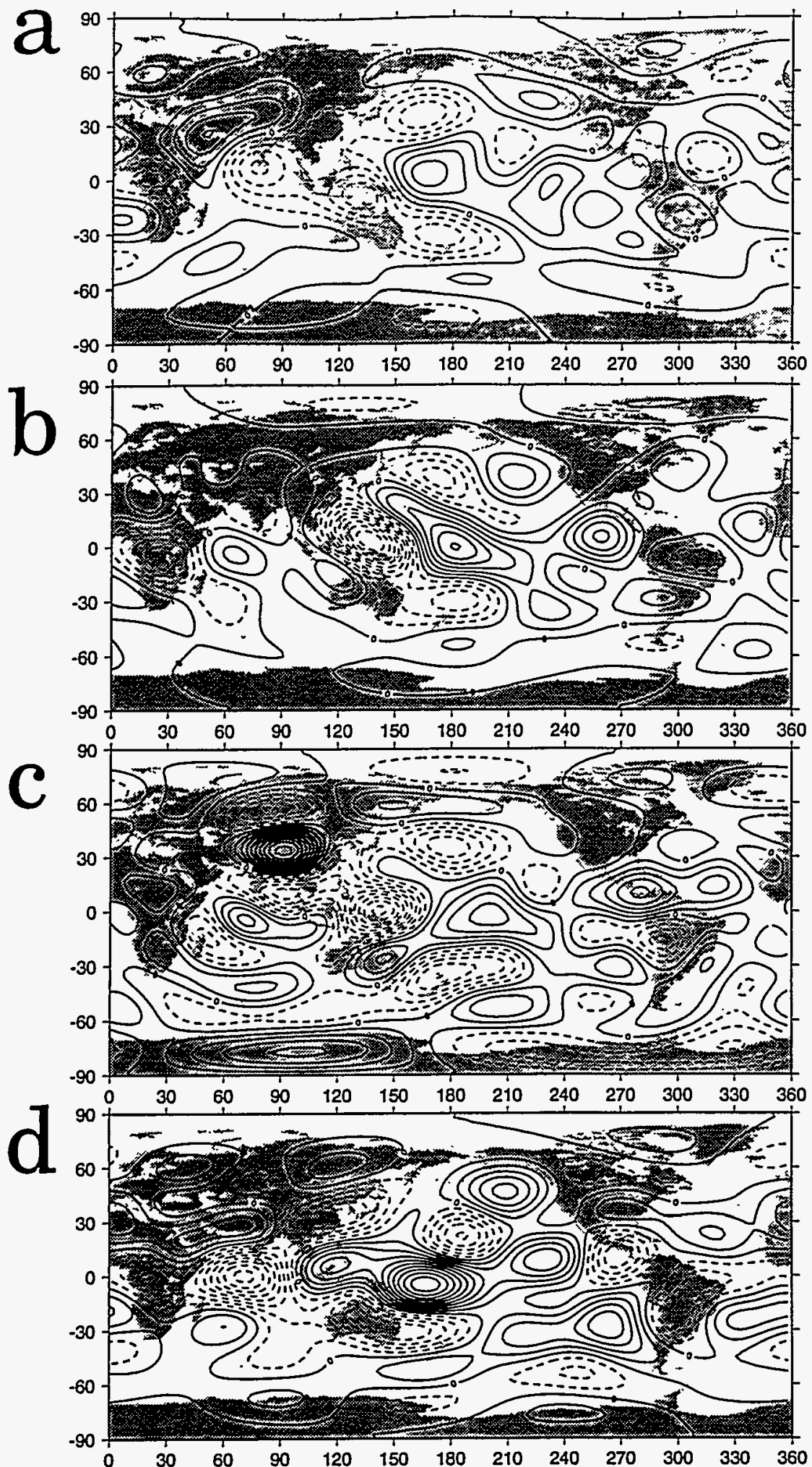

Figure 5. The $200 \mathrm{hPa}$ divergence fields computed from the leading principal vectors of the $200 \mathrm{hPa}$ velocity potential in spherical harmonics for (a) the NMC analyses, (b) CCC, (c) SUNYA, (d) MPI. The solid contours are for positive values and zero, the negative contours are dashed. The contour interval is $0.1 \times 10^{-6} \mathrm{sec}^{-1}$. 


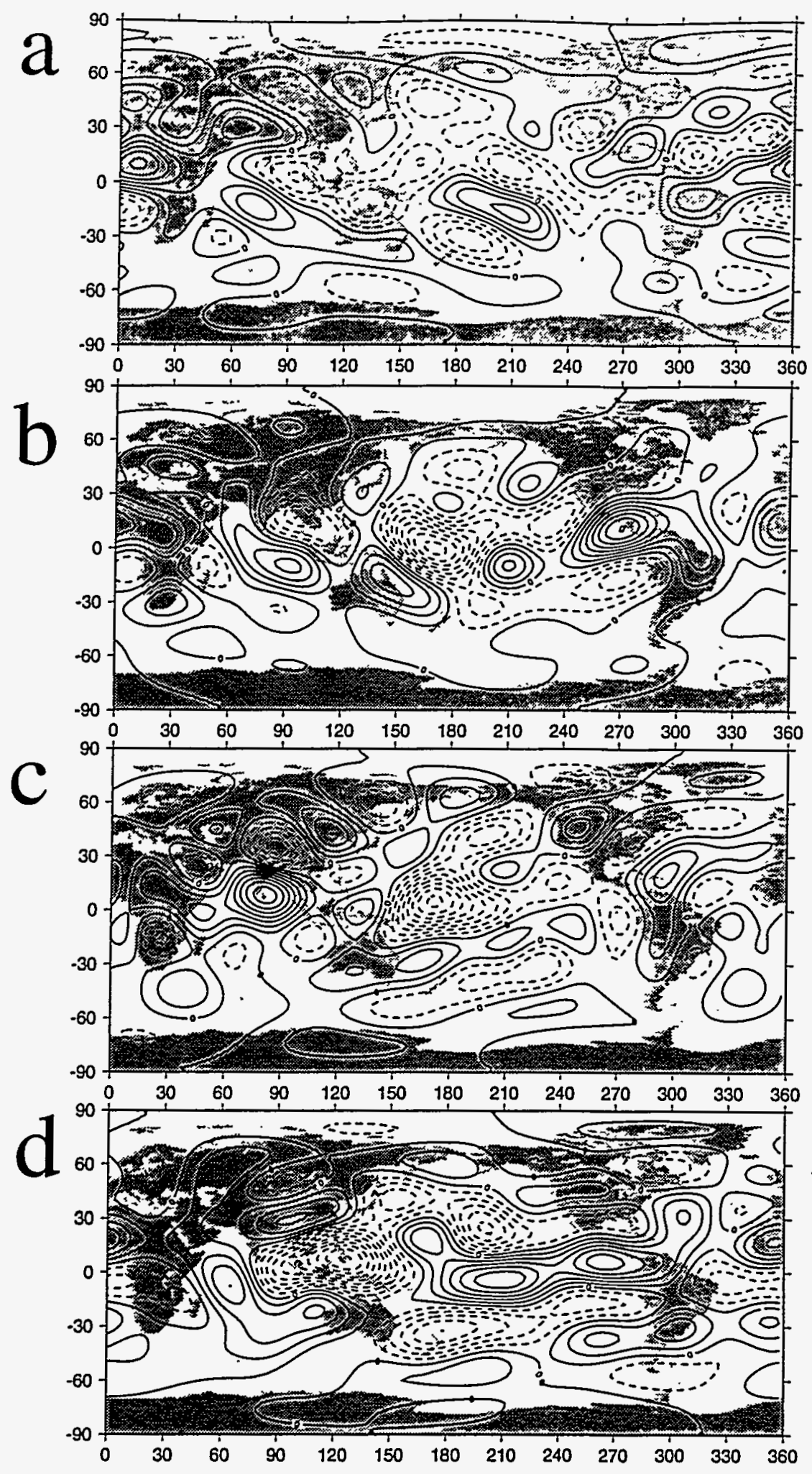

Figure 6. The $200 \mathrm{hPa}$ divergence fields computed from the 2 nd principal vectors of the $200 \mathrm{hPa}$ velocity potential in spherical harmonics for (a) the NMC analyses, (b) CCC, (c) SUNYA, (d) MPI. The solid contours are for positive values and zero, the negative contours are dashed. The contour interval is $0.1 \times 10^{-6} \mathrm{sec}^{-1}$. 


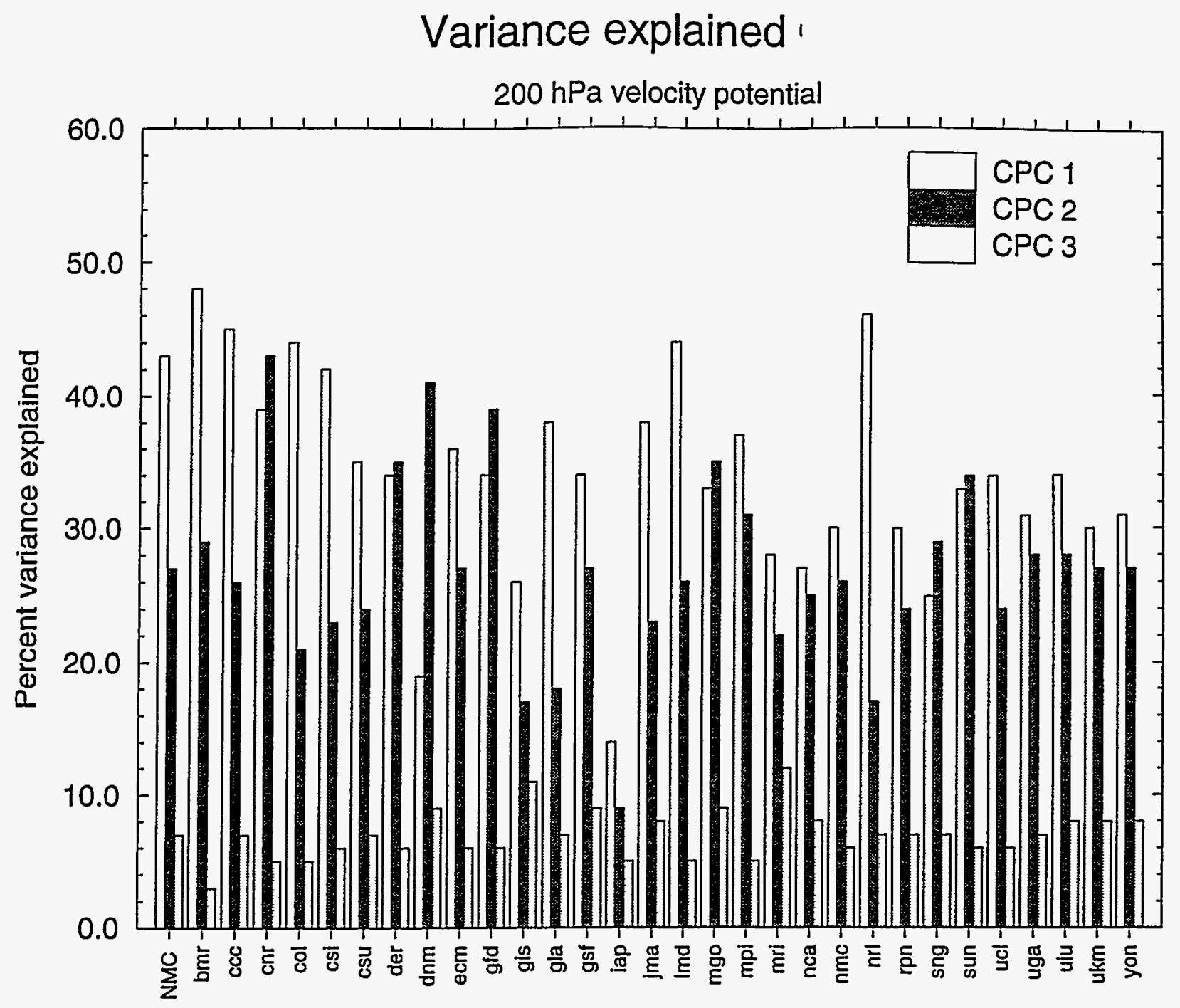

Figure 7. Bar chart of the percent variance explained by the leading three CPCs for the $200 \mathrm{hPa}$ velocity potential for the AMIP simulations and NMC analysis. 


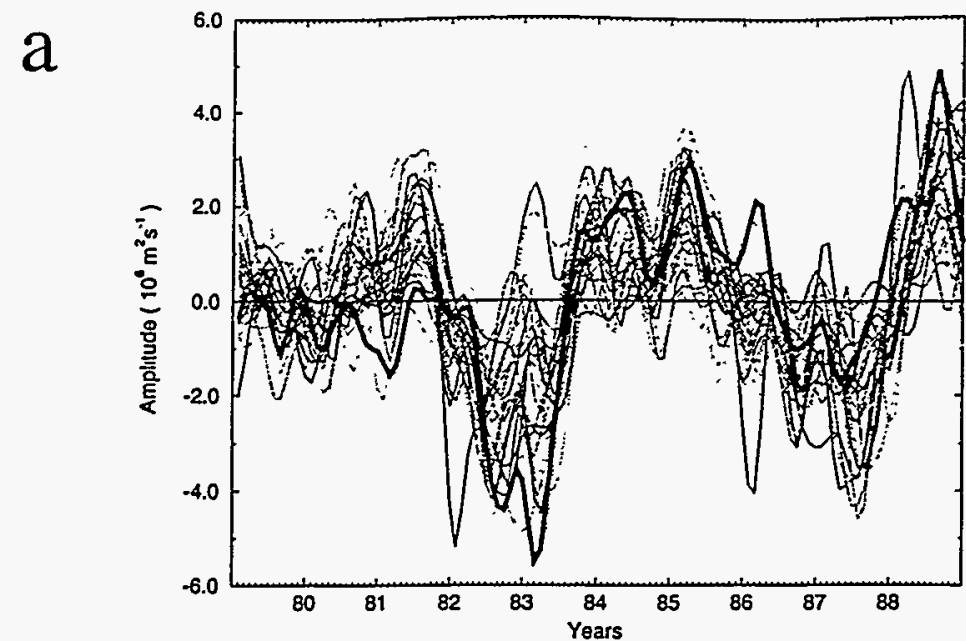

b
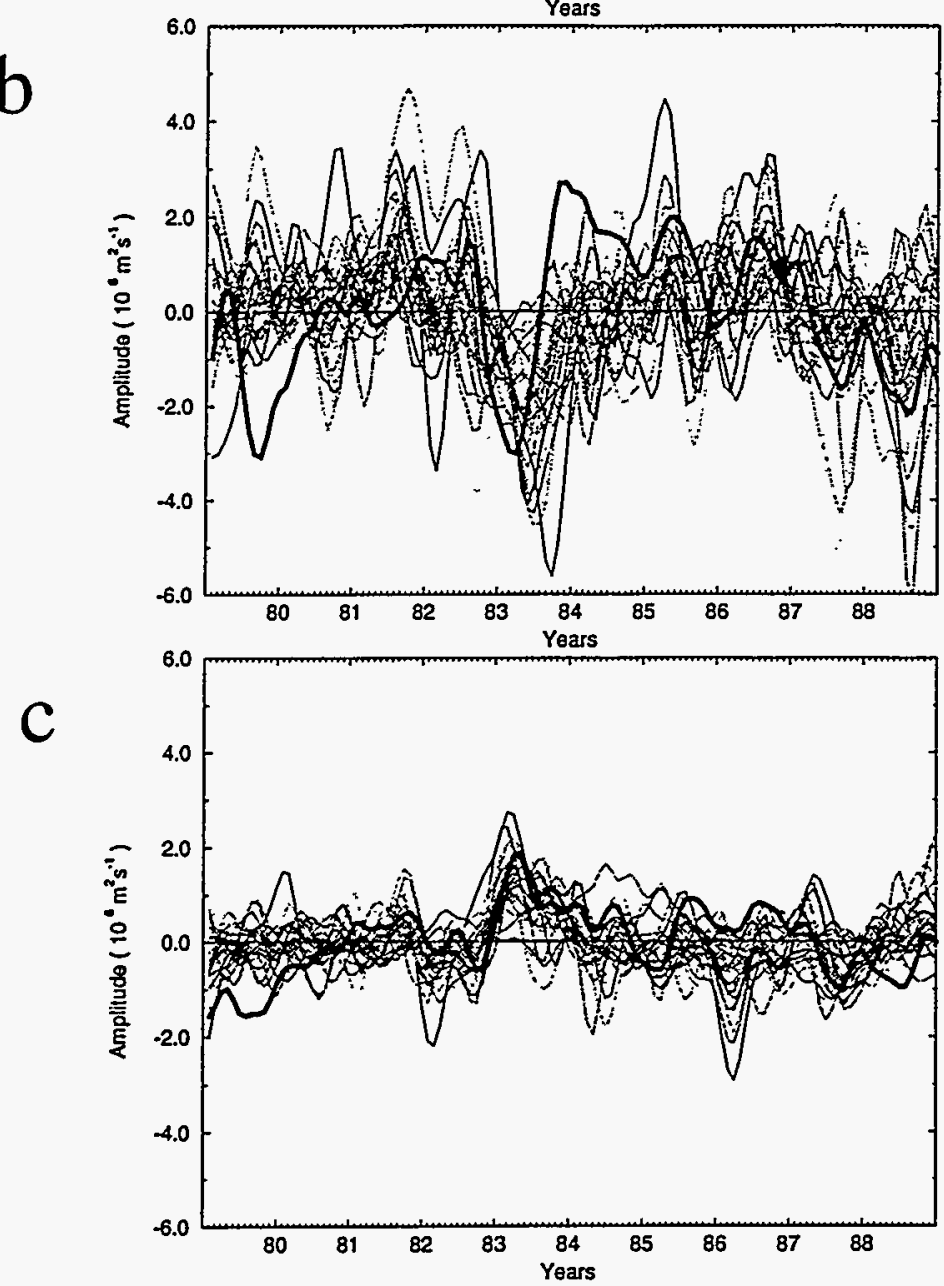

Figure 8. Time series of the common principal components of the $200 \mathrm{hPa}$ velocity potential for the AMIP models and the NMC analysis. (a) First component, (b) second component , (c) third component. Ordering based on NMC analyses (see text). Thick dashed line is the NMC analysis. 


\section{Correlation (PC, SOI)}

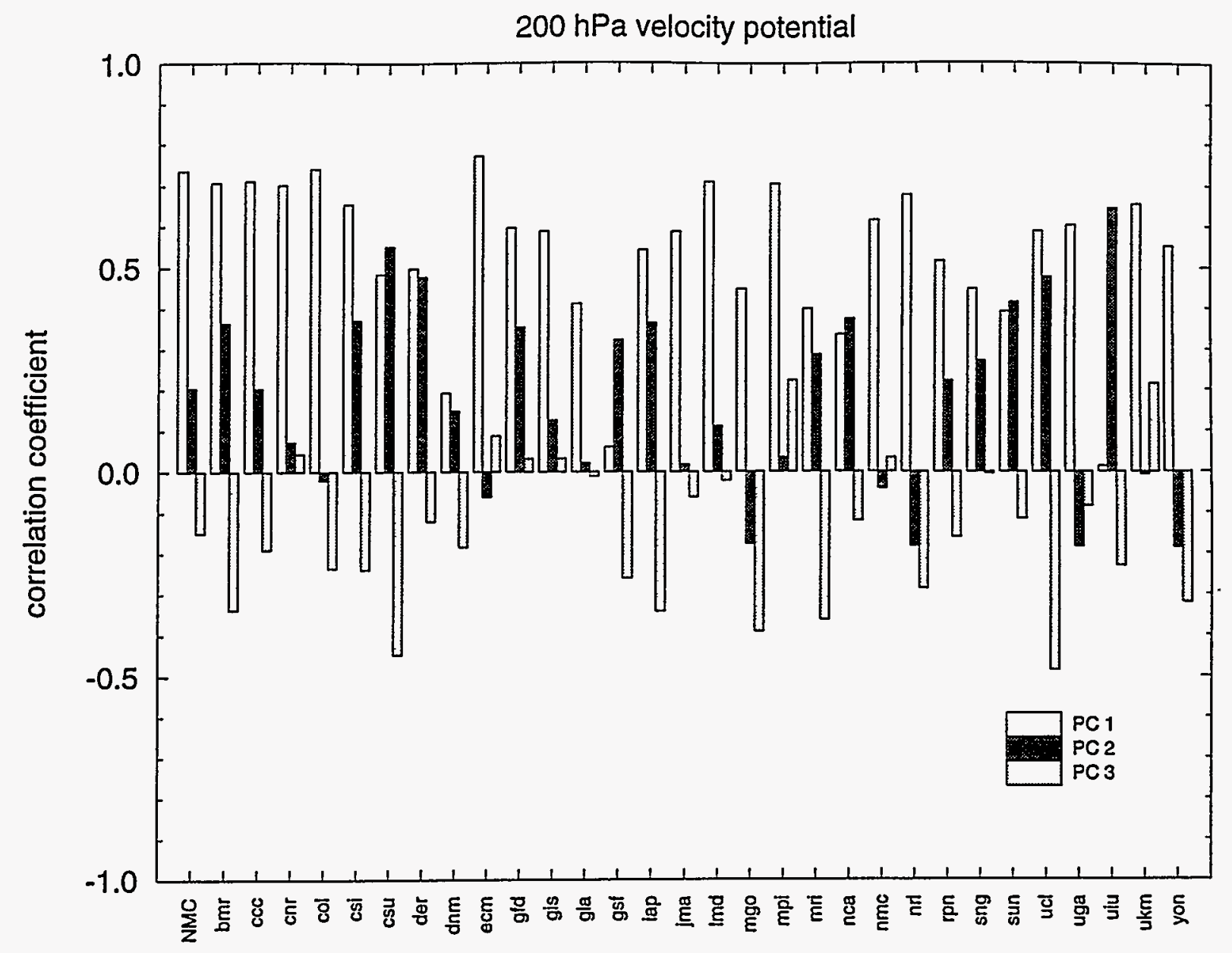

Figure 9. Bar chart of the linear correlation coefficient between the time series of the first CPCs for the $200 \mathrm{hPa}$ velocity potential, Fig.8, and the SOI, Fig. 3. 

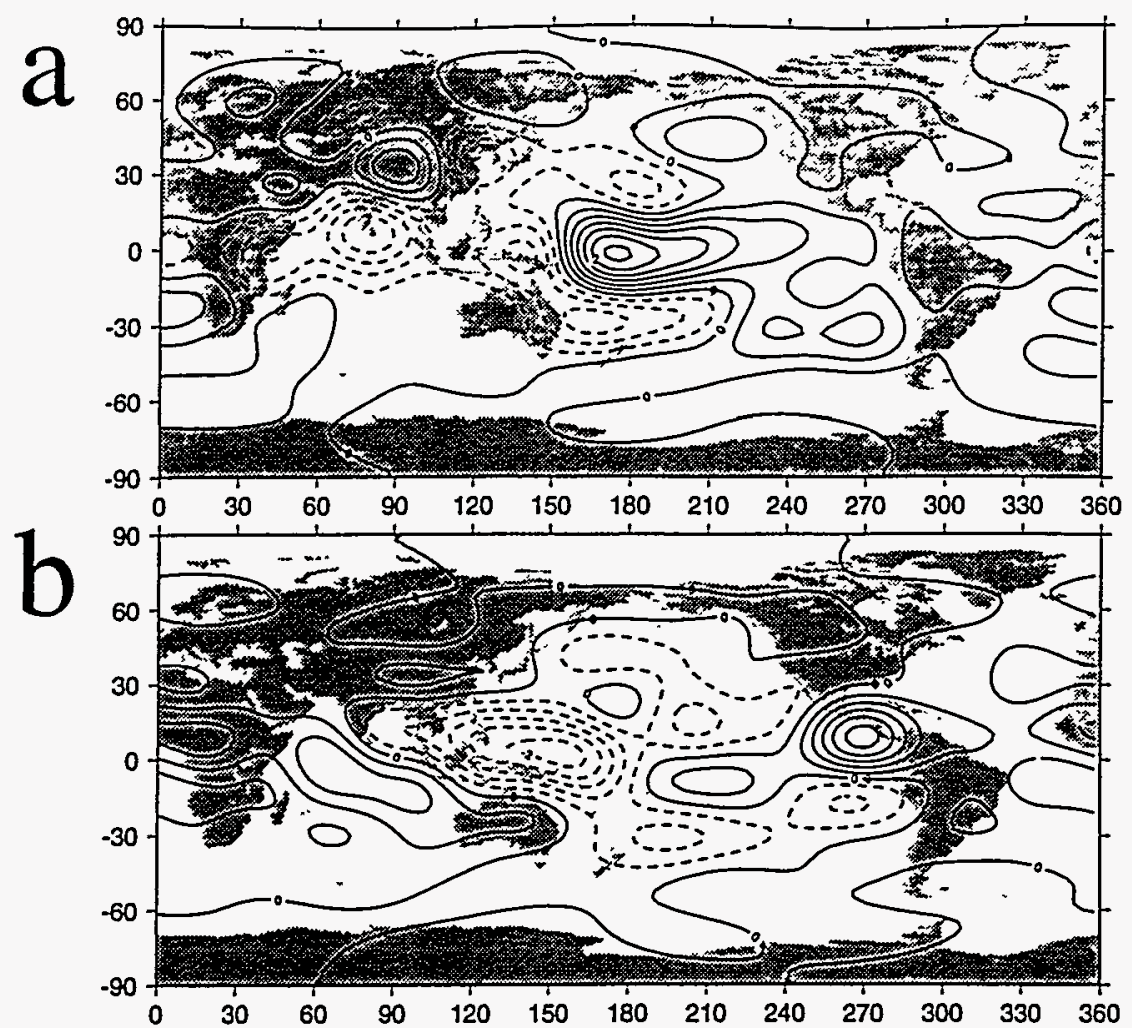

Figure 10. The $200 \mathrm{hPa}$ divergence fields computed from the leading common principal vectors of the $200 \mathrm{hPa}$ velocity potential in spherical harmonics for (a) first CPC, (b) second CPC. The solid contours are for positive values and zero, the negative contours are dashed. The contour interval is $0.1 \times 10^{-6}$ $\mathrm{sec}^{-1}$. CPC ordering based on NMC analyses (see text). 


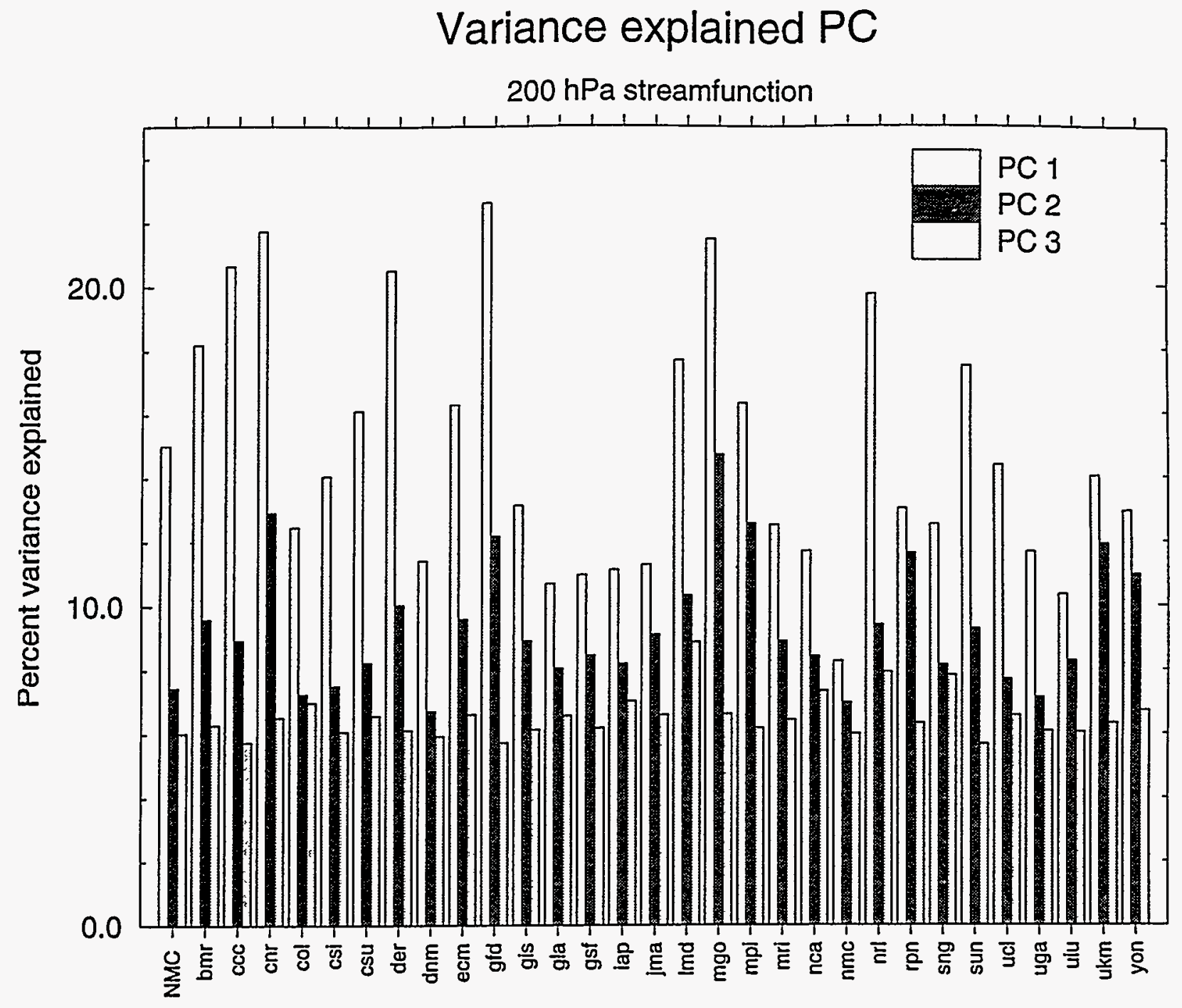

Figure 11. Bar chart of the percent variance explained by the leading three PCs for the $200 \mathrm{hPa}$ streamfunction for the AMIP simulations and NMC analysis. 

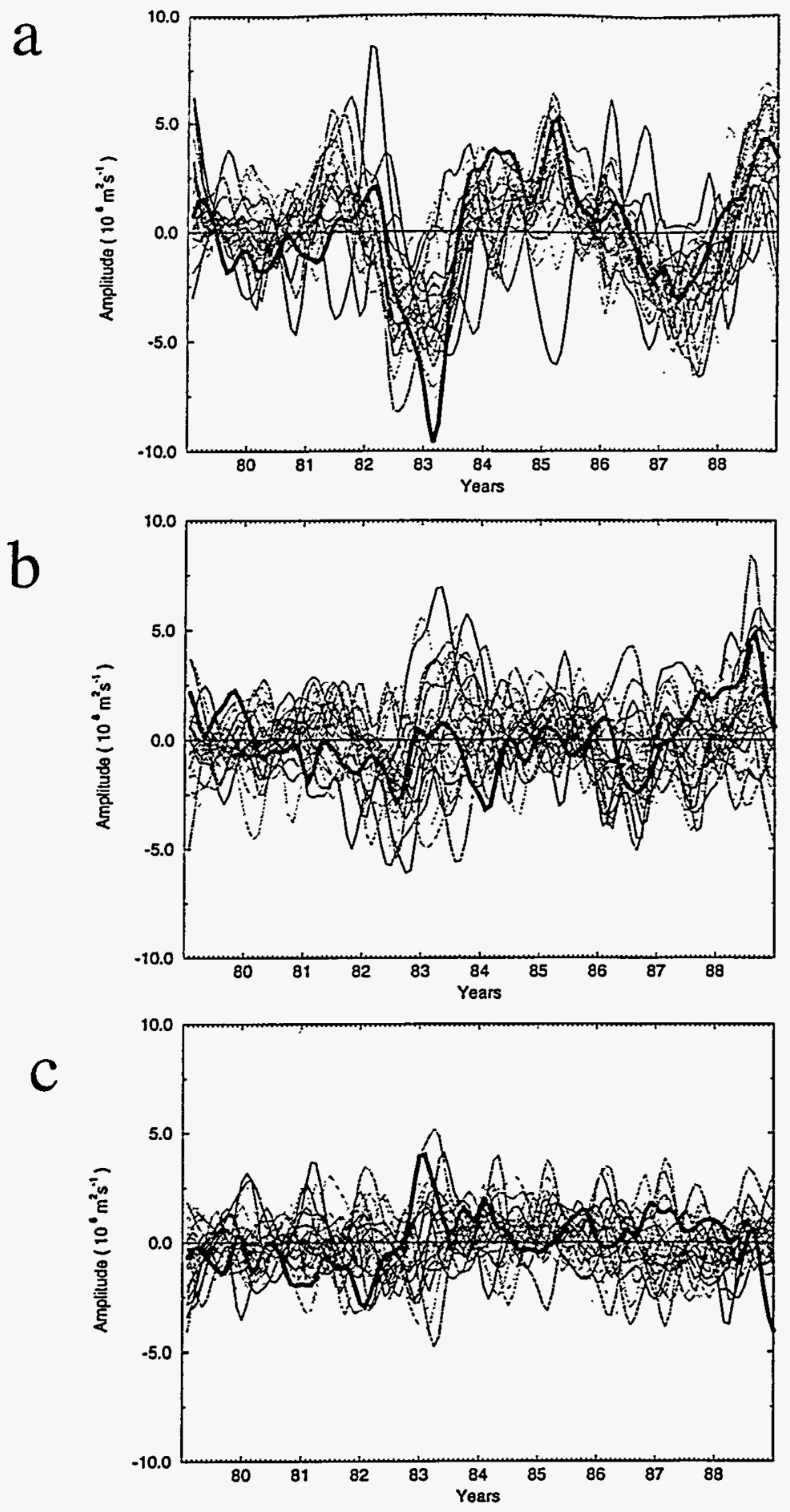

Figure 12. Time series of the principal components of the $200 \mathrm{hPa}$ streamfunction for the AMIP models and the NMC analysis. (a) First component for each model, (b) second for each model, (c) third for each model. The thick line is the NMC analysis. 


\section{Correlation (PC, SOI)}

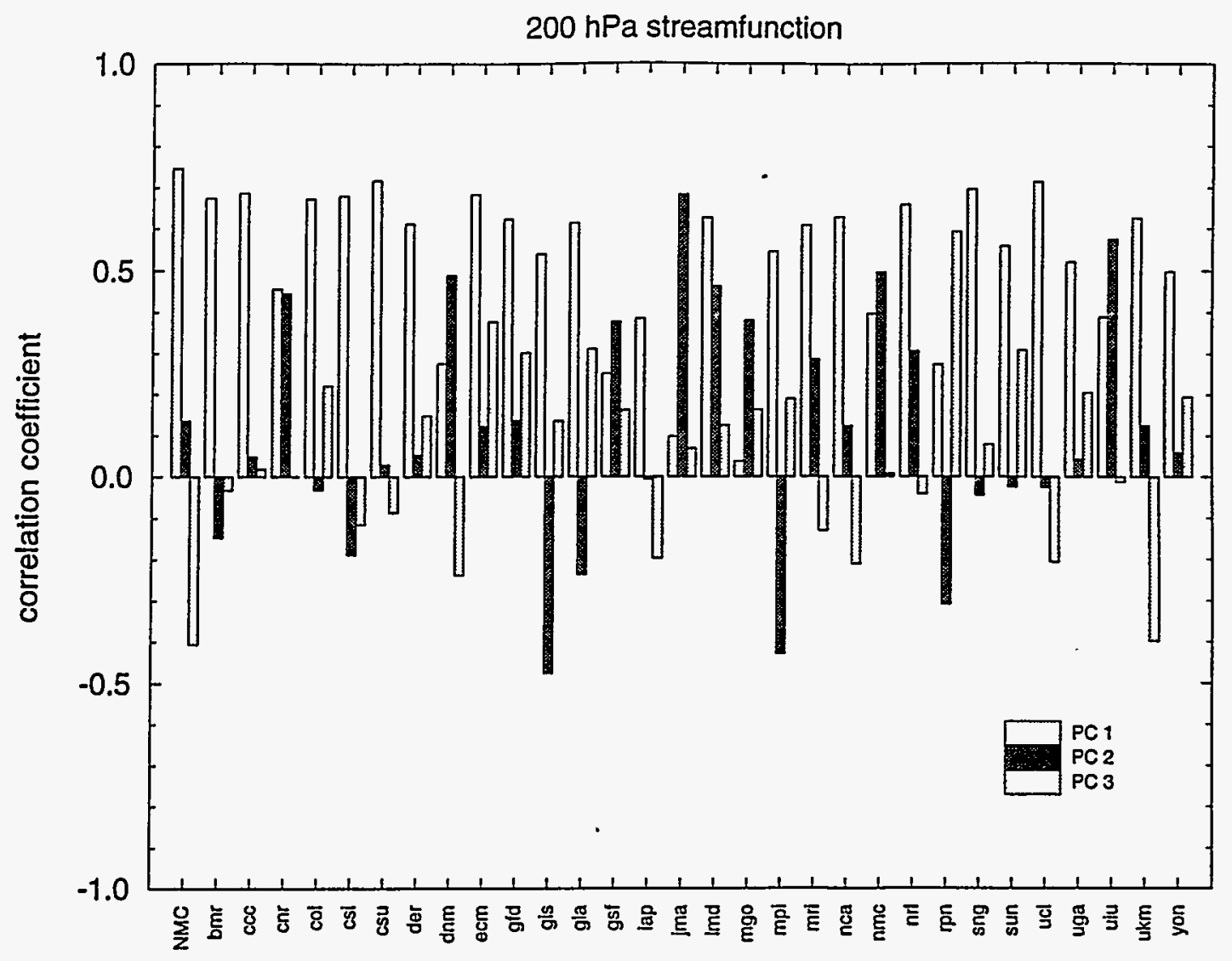

Figure 13. Bar chart of the linear correlation coefficient between the time series of the first three PCs for the $200 \mathrm{hPa}$ streamfunction, Fig.12, and the SOI, Fig. 3. 

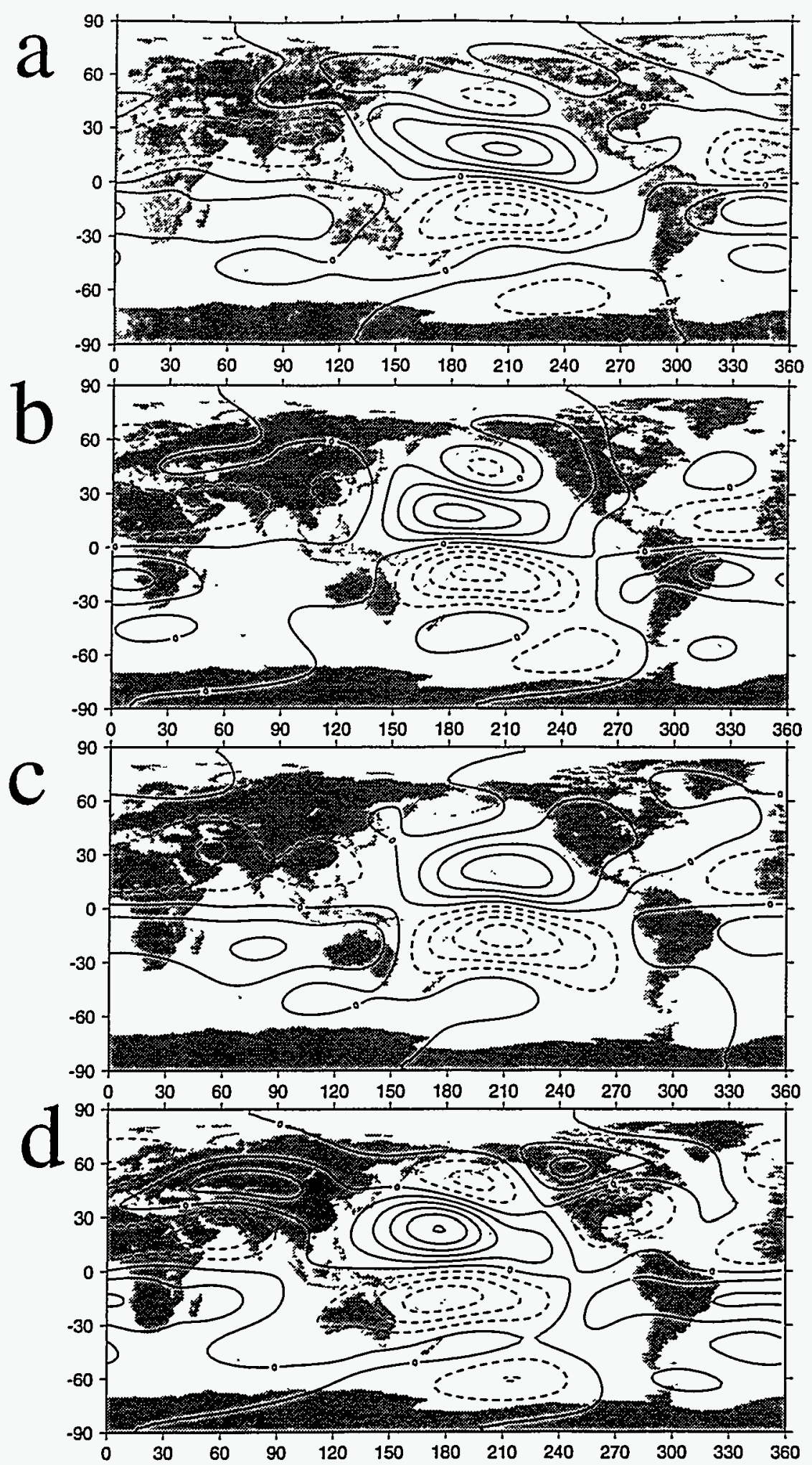

Figure 14. The leading principal vectors of the $200 \mathrm{hPa}$ streamfunction for (a) the NMC analyses, (b) CCC, (c) SUNYA, (d) MPI. The solid contours are for positive values and zero, the negative contours are dashed. The contour interval is $0.1 \times 10^{6} \mathrm{~m}^{2} \mathrm{sec}^{-1}$. 

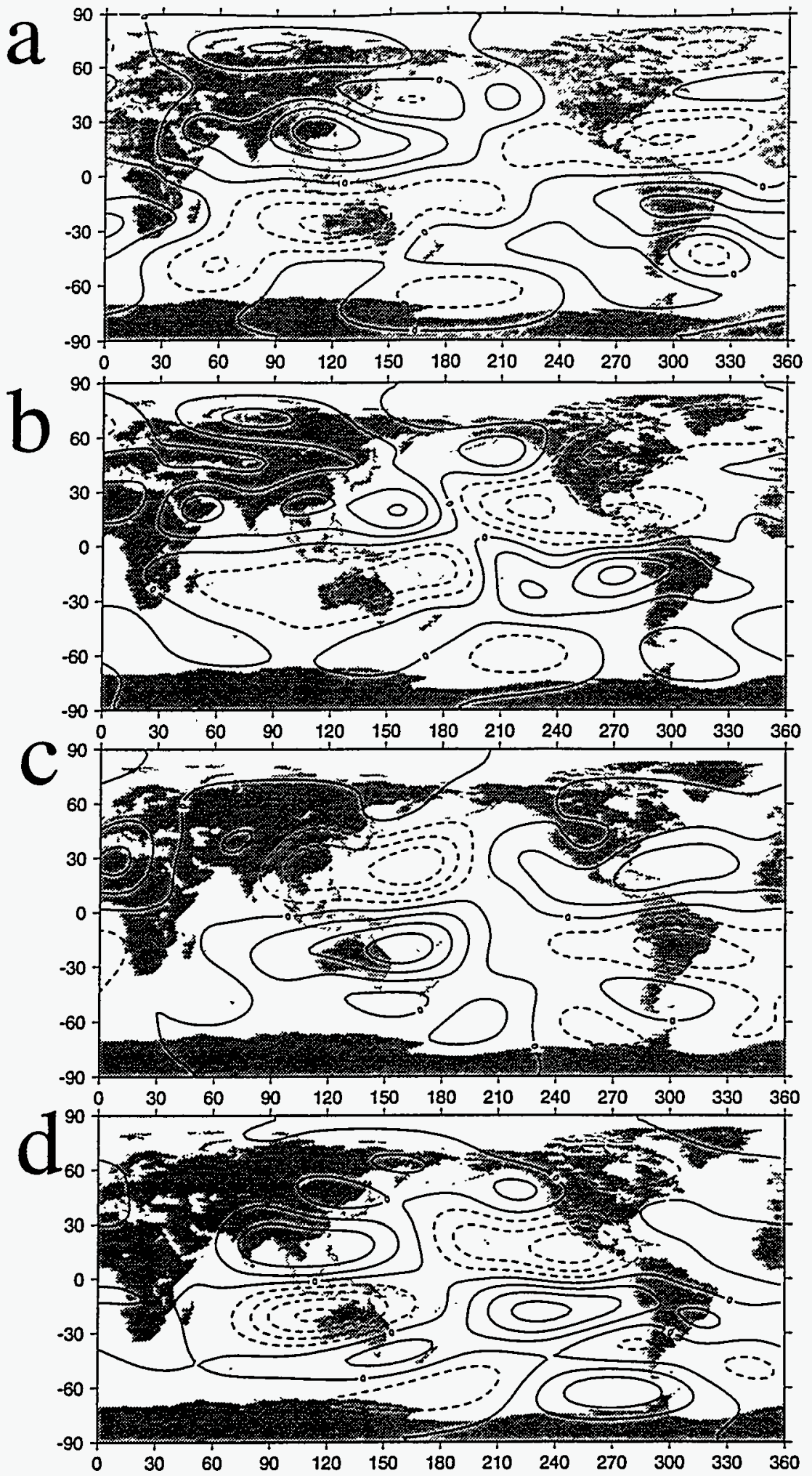

Figure 15. The second principal vectors of the $200 \mathrm{hPa}$ streamfunction for (a) the NMC analyses, (b) CCC, (c) SUNYA, (d) MPI. The solid contours are for positive values and zero, the negative contours are dashed. The contour interval is $0.1 \times 10^{6} \mathrm{~m}^{2} \mathrm{sec}^{-1}$. 


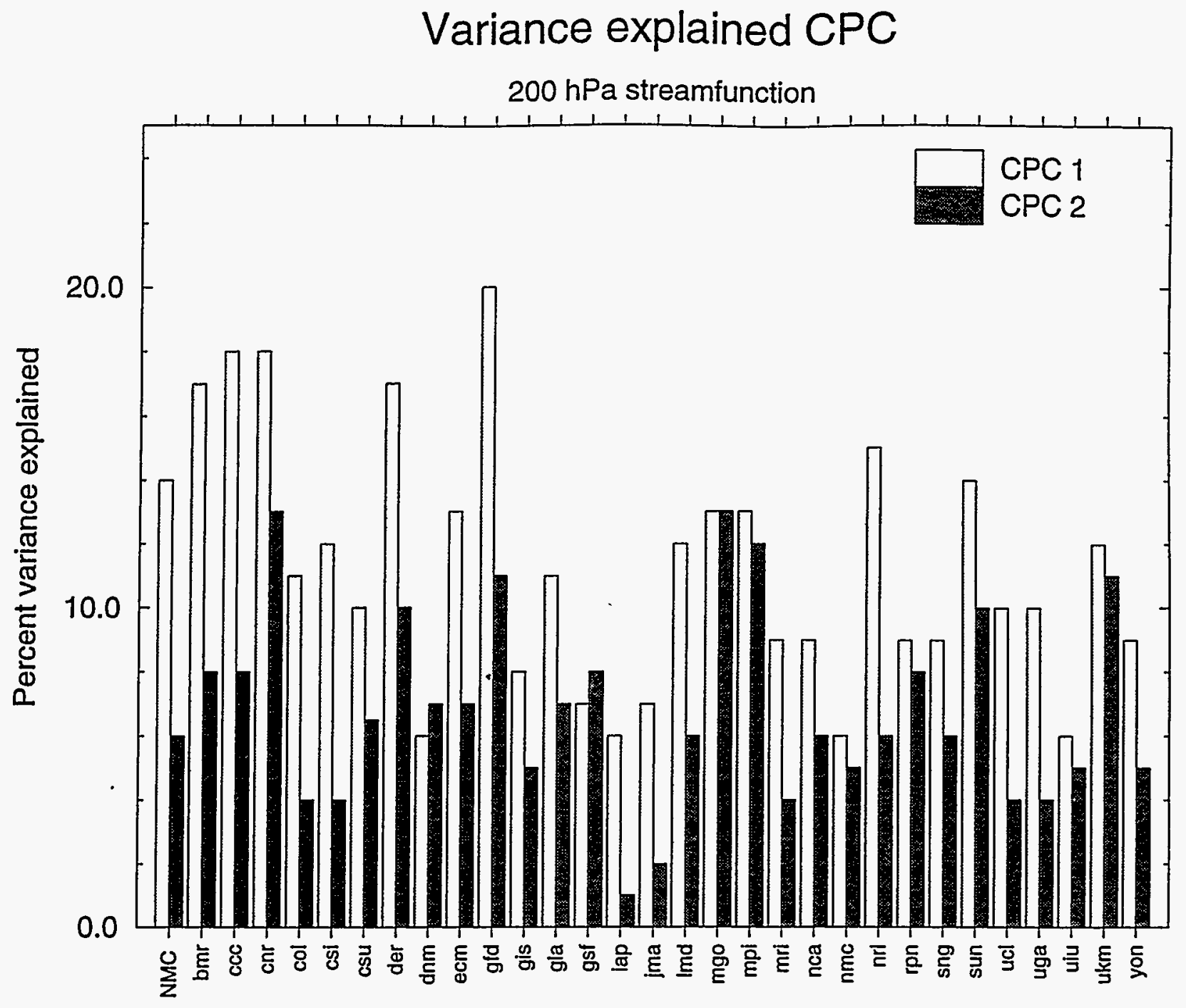

Figure 16. Bar chart of the percent variance explained by the leading two CPCs for the $200 \mathrm{hPa}$ streamfunction for the AMIP simulations and NMC analysis. 

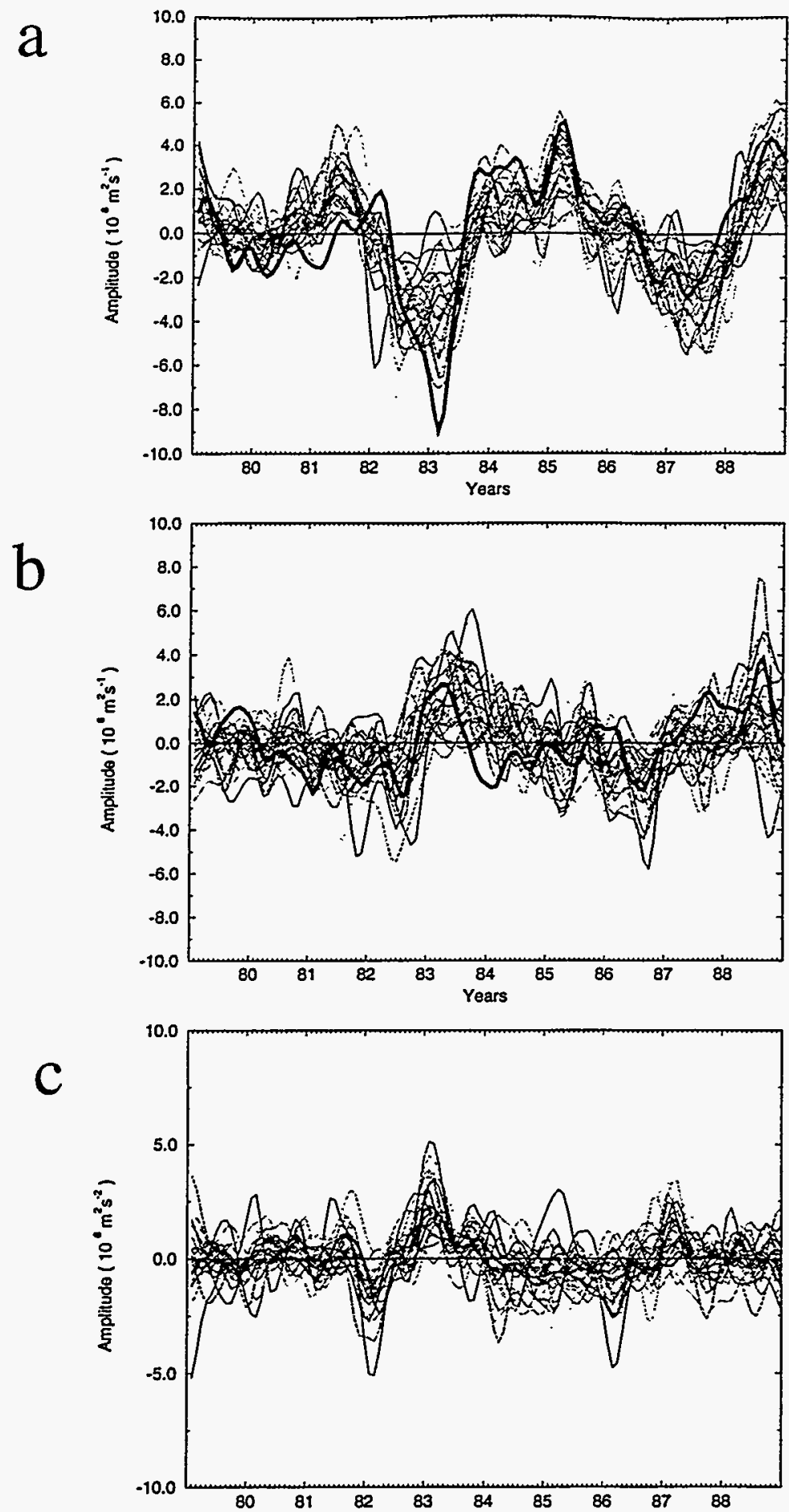

Figure 17. Time series of the common principal components of the $200 \mathrm{hPa}$ streamfunction for the AMIP models and the NMC analysis. (a) First component, (b) second component, (c) third component. Ordering based on NMC analyses (see text). 


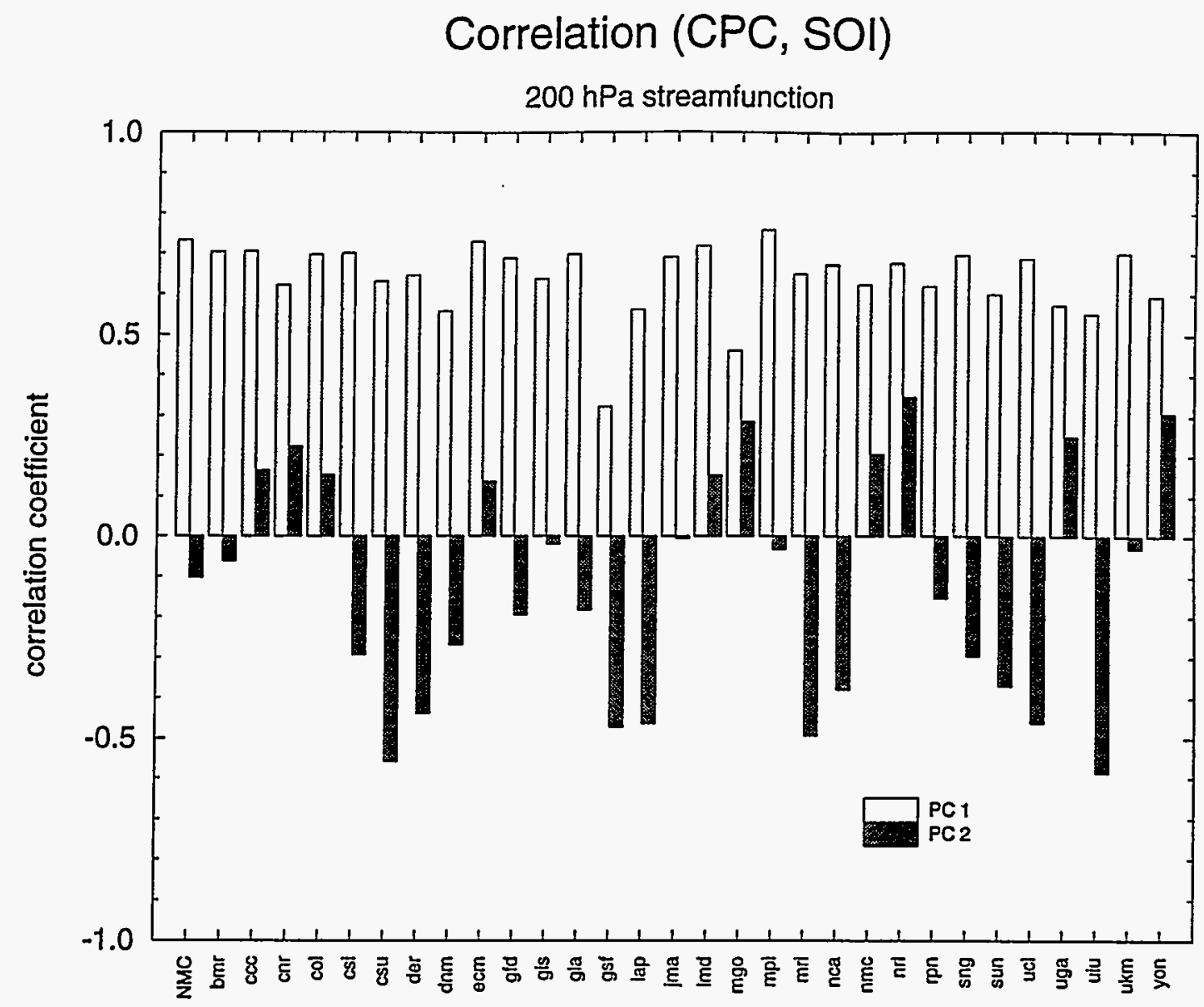

Figure 18. Bar chart of the linear correlation coefficient between the time series of the first two CPCs for the $200 \mathrm{hPa}$ streamfunction, Fig.17, and the SOI, Fig. 3. 


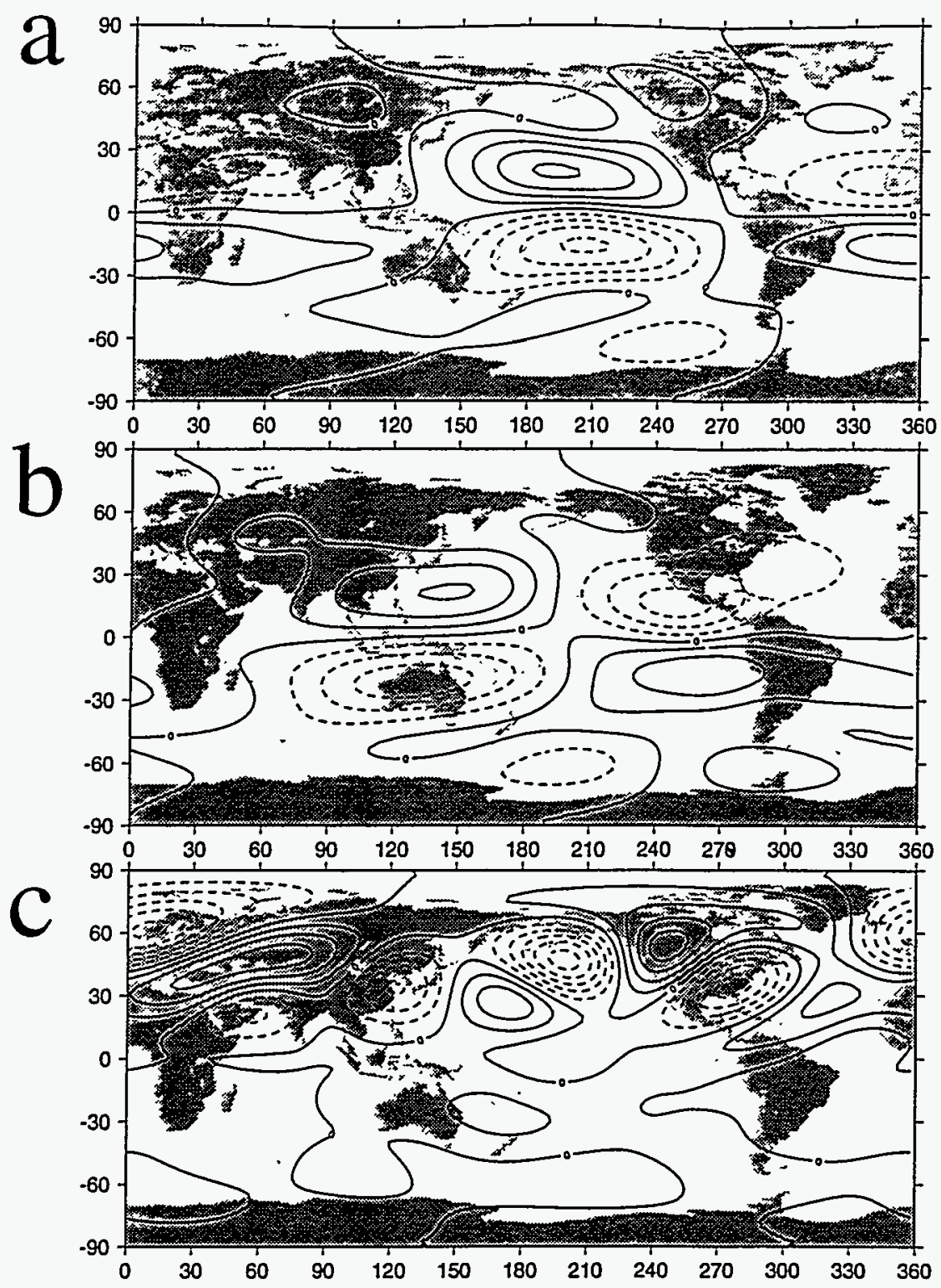

Figure 19. The leading common principal vectors of the $200 \mathrm{hPa}$ streamfunction for (a) first CPC , (b) second CPC, (c) Third CPC. The solid contours are for positive values and zero, the negative contours are dashed.The contour interval is $0.1 \times 10^{6} \mathrm{~m}^{2} \mathrm{sec}^{-1}$. CPC ordering based on NMC analyses (see text). 
a

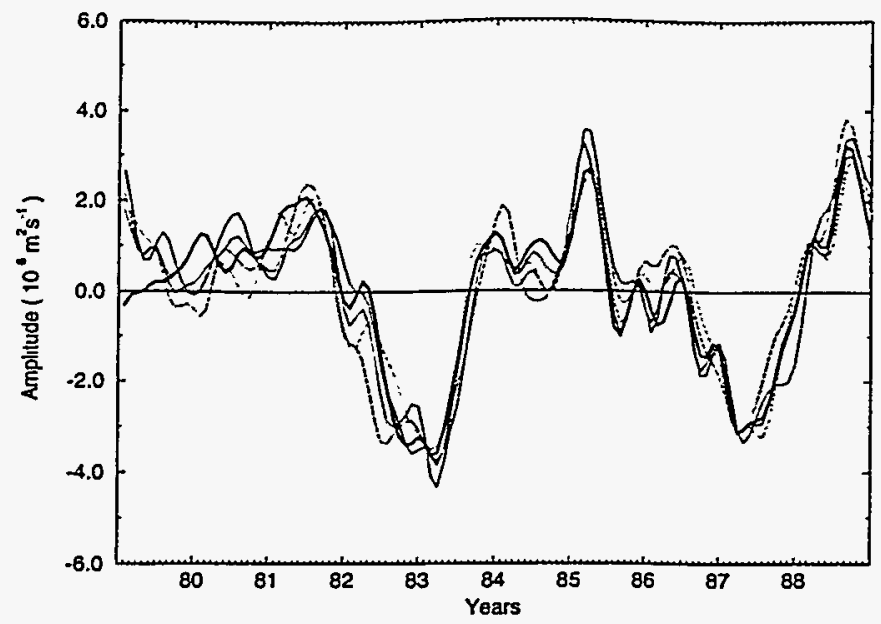

b

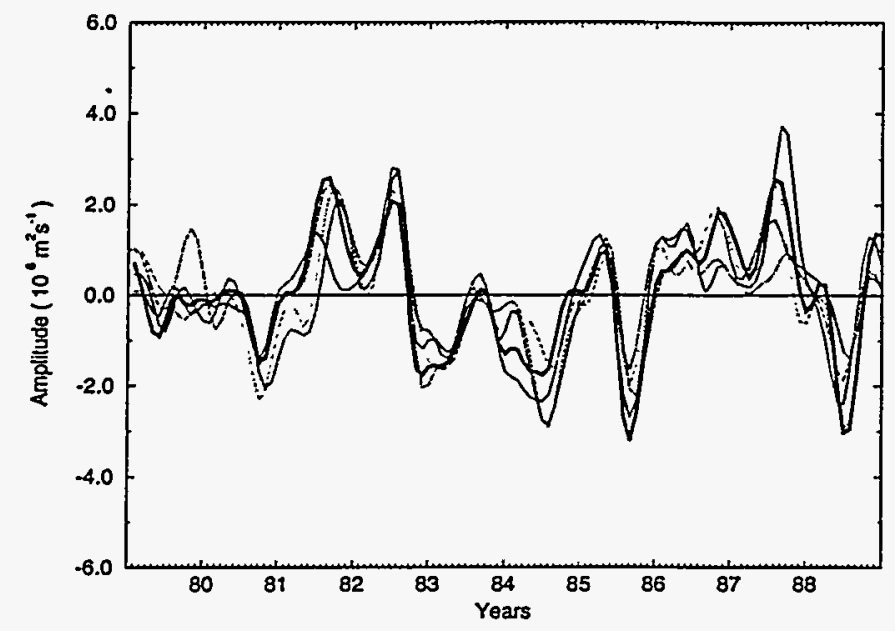

Figure 20. Time series of the common principal components of the $200 \mathrm{hPa}$ velocity potential for five ensemble simulations of the ECMWF GCM. (a) First component, (b) second component. The thick line is the ECMWF AMIP simulation. 

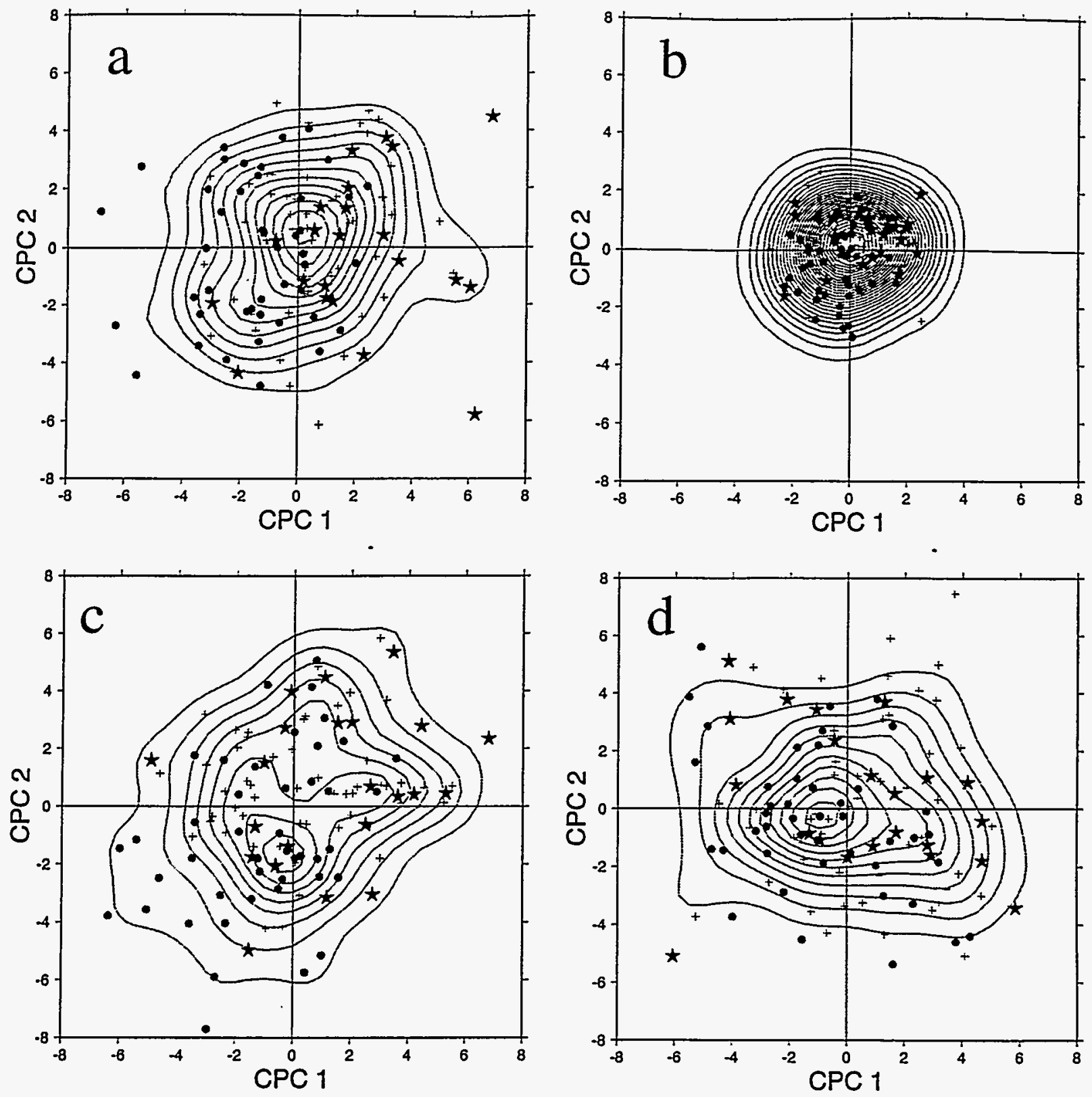

Figure 21. Probability density contours for the space defined by CPC 1 and CPC 2 of the $200 \cdot \mathrm{hPa}$ velocity potential for (a), the NMC analyses, (b) CSU, (c) DERF, and d) GLA. The abscissa is CPC 1, and the ordinate is CPC 2. The filled circles represent points of low SOI index (less than -0.5 ) and the stars are points of high SOI index ( above 0.5 ), while the crosses are intermediate values. 


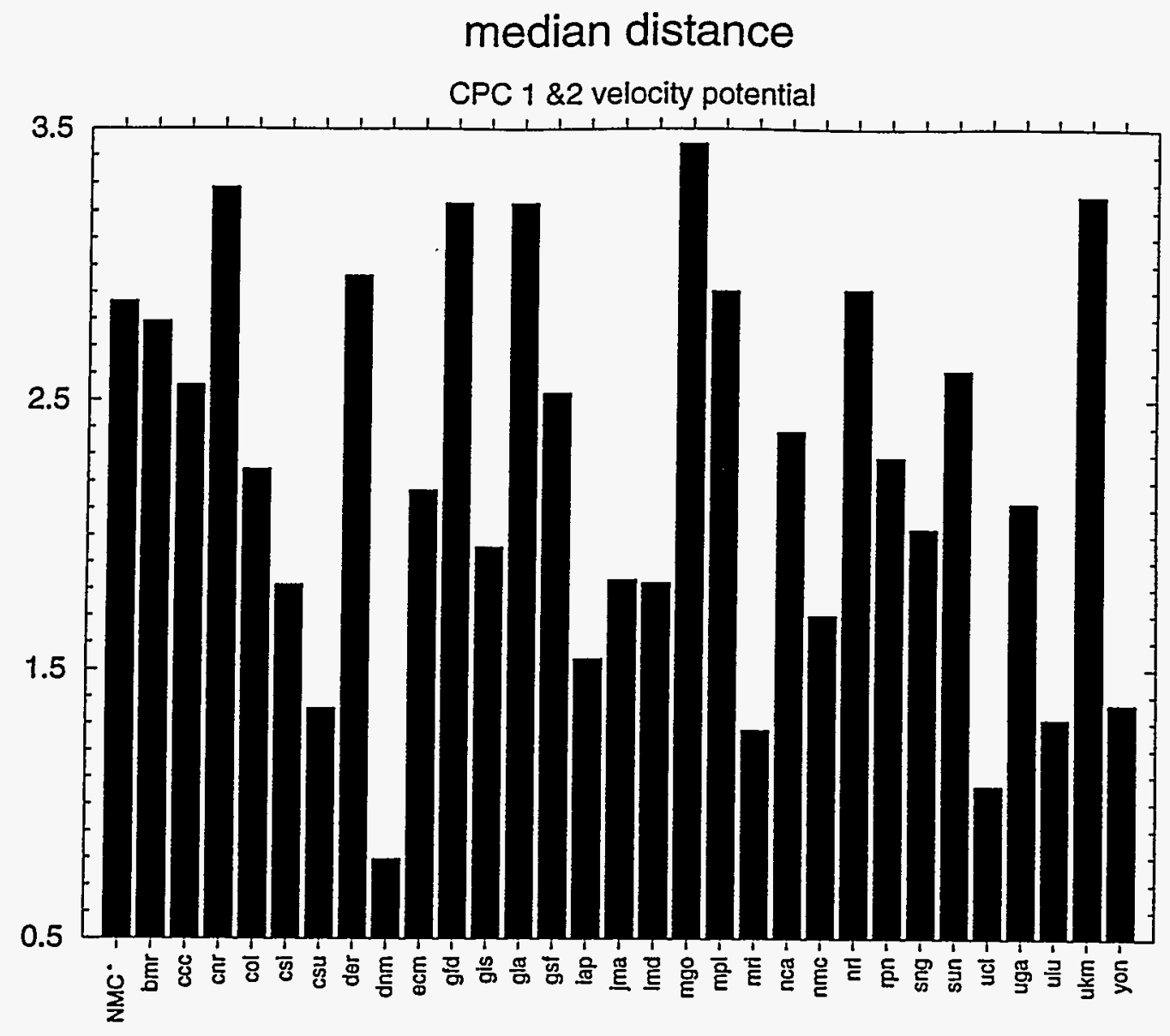

Figure 22. The median distance from the origin for the AMIP models and NMC analyses for the space defined by CPC 1 and CPC 2 for the $200 \mathrm{hPa}$ velocity potential. 

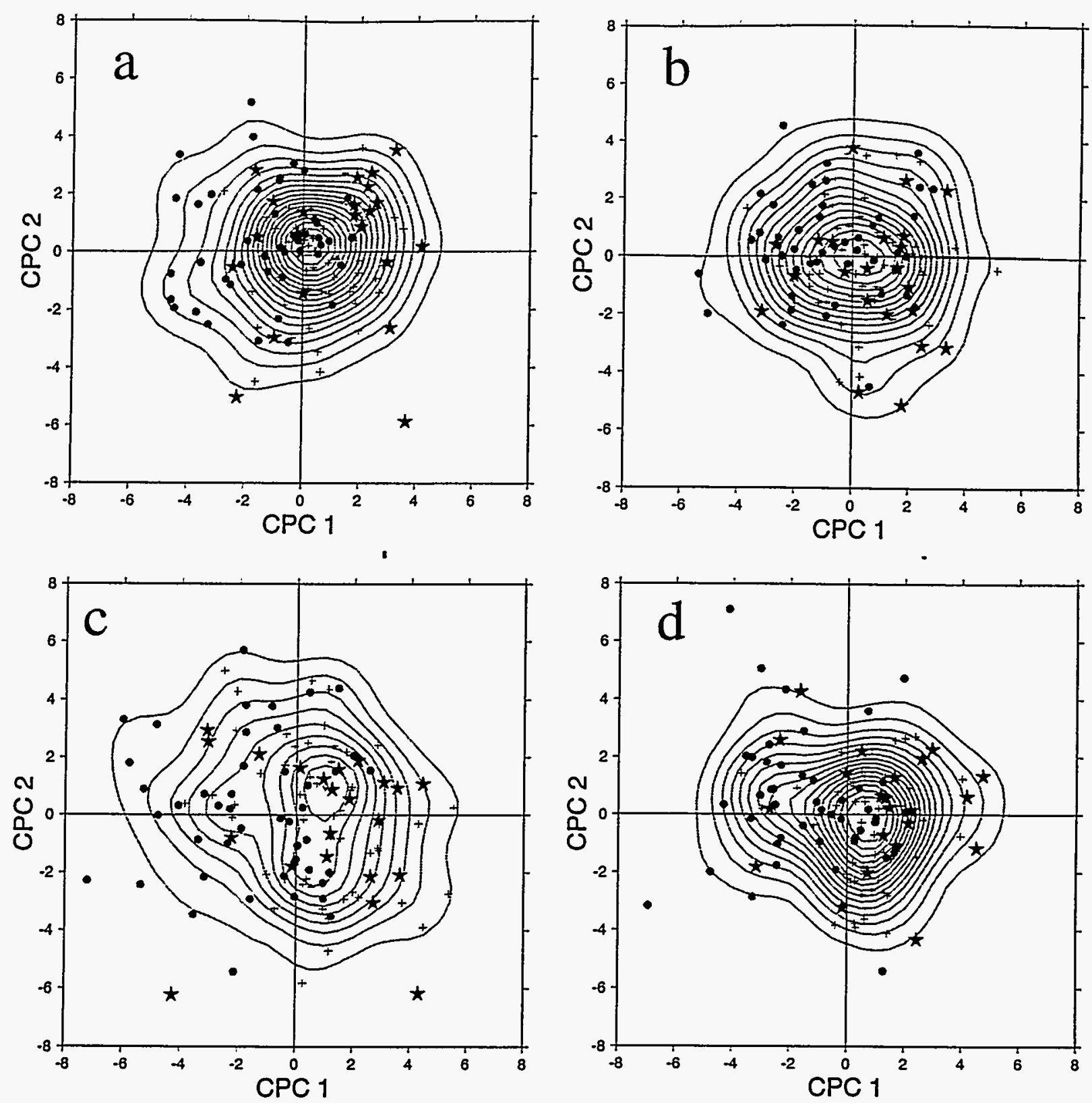

Figure 23. As in Fig. 21 except for (a) the ECMWF, (b) UGAMP, (c) MPI, (d) one member of the ECMWF ensemble integration. 


\section{DISCLAIMER}

This report was prepared as an account of work sponsored by an agency of the United States Government. Neither the United States Government nor any agency thereof, nor any of their employees, makes any warranty, express or implied, or assumes any legal liability or responsibility for the accuracy, completeness, or usefulness of any information, apparatus, product, or process disclosed, or represents that its use would not infringe privately owned rights. Reference herein to any specific commercial product, process, or service by trade name, trademark, manufacturer, or otherwise does not necessarily constitute or imply its endorsement, recommendation, or favoring by the United States Government or any agency thereof. The views and opinions of authors expressed herein do not necessarily state or reflect those of the United States Government or any agency thereof. 


\section{DISCLAIMER}

This document was prepared as an account of work sponsored by an agency of the United States Government. Neither the United States Government nor the University of Califomia nor any of their employees, makes any warranty, express or implied, or assumes any legal liability or responsibility for the accuracy, completeness, or usefulness of any information, apparatus, product, or process disclosed, or represents that its use would not infringe privately owned rights. Reference herein to any specific commercial product, process, or service by trade name, trademark, manufacturer, or otherwise, does not necessarily constitute or imply its endorsement, recommendation, or favoring by the United States Government or the University of California. The views and opinions of authors expressed herein do not necessarily state or reflect those of the United States Government or the University of Califomia, and shall not be used for advertising or product endorsement purposes.

This is an informal report intended primarily for internal or limited external distribution. The opinions and conclusions stated are those of the author and may or may not be those of the Laboratory.

This report has been reproduced

directly from the best available copy.

Available to DOE and DOE contractors from the

Office of Scientific and Technical Information

P.O. Box 62, Oak Ridge, TN 37831

Prices available from (615) 576-8401, FTS 626-8401

Available to the public from the

National Technical Information Service

U.S. Department of Commerce

5285 Port Royal Rd.,

Springfield, VA 22161 